\title{
A Framework for Understanding the Emerging Role of Corticolimbic-Ventral Striatal Networks in OCD-Associated Repetitive Behaviors
}

\author{
Jesse Wood ${ }^{1,2}$ and Susanne E. Ahmari ${ }^{1,2,3 *}$ \\ ${ }^{1}$ Translational Neuroscience Program, Department of Psychiatry, University of Pittsburgh, Pittsburgh, PA, USA, ${ }^{2}$ Center for \\ Neuroscience, University of Pittsburgh, Pittsburgh, PA, USA, ${ }^{3}$ Center for the Neural Basis of Cognition, University of \\ Pittsburgh, Pittsburgh, PA, USA
}

Significant interest in the mechanistic underpinnings of obsessive-compulsive disorder (OCD) has fueled research on the neural origins of compulsive behaviors. Converging clinical and preclinical evidence suggests that abnormal repetitive behaviors are driven by dysfunction in cortico-striatal-thalamic-cortical (CSTC) circuits. These findings suggest that compulsive behaviors arise, in part, from aberrant communication between lateral

OPEN ACCESS

Edited by:

Melissa Rhoads Warden,

Cornell University, USA

Reviewed by:

Vikaas Singh Sohal,

University of California, San

Francisco, USA

Eric Burguière,

Centre National de Recherche

Scientifique, France

Mazen A. Kheirbek,

Columbia University, USA

*Correspondence:

Susanne E. Ahmari

ahmarise@upmc.edu

Received: 18 August 2015 Accepted: 23 November 2015 Published: 17 December 2015

Citation:

Wood J and Ahmari SE (2015) A Framework for Understanding the Emerging Role of

Corticolimbic-Ventral Striatal Networks in OCD-Associated Repetitive Behaviors.

Front. Syst. Neurosci. 9:171. doi: 10.3389/fnsys.2015.00171 orbitofrontal cortex (OFC) and dorsal striatum. An important body of work focused on the role of this network in OCD has been instrumental to progress in the field. Disease models focused primarily on these regions, however, fail to capture an important aspect of the disorder: affective dysregulation. High levels of anxiety are extremely prevalent in OCD, as is comorbidity with major depressive disorder. Furthermore, deficits in processing rewards and abnormalities in processing emotional stimuli are suggestive of aberrant encoding of affective information. Accordingly, OCD can be partially characterized as a disease in which behavioral selection is corrupted by exaggerated or dysregulated emotional states. This suggests that the networks producing OCD symptoms likely expand beyond traditional lateral OFC and dorsal striatum circuit models, and highlights the need to cast a wider net in our investigation of the circuits involved in generating and sustaining OCD symptoms. Here, we address the emerging role of medial OFC, amygdala, and ventral tegmental area projections to the ventral striatum (VS) in OCD pathophysiology. The VS receives strong innervation from these affect and reward processing regions, and is therefore poised to integrate information crucial to the generation of compulsive behaviors. Though it complements functions of dorsal striatum and lateral OFC, this corticolimbic-VS network is less commonly explored as a potential source of the pathology underlying OCD. In this review, we discuss this network's potential role as a locus of OCD pathology and effective treatment.

Keywords: OCD (obsessive-compulsive disorder), compulsive behavior, amygdala, dopamine, OFC, ventral striatum, accumbens, network 


\section{REPETITIVE BEHAVIORS IN OBSESSIVE-COMPULSIVE DISORDER MAY BE DRIVEN BY DYSREGULATION OF CORTICOLIMBIC AND VENTRAL STRIATAL NETWORKS}

The basic architecture of neuronal circuits creates a system rich with opportunities for interactions between brain regions. These interregional functional neuronal connections are fundamental to cognition, and when disrupted, can contribute to numerous pathologies (Singer and Gray, 1995; Crick and Koch, 2003; Knight, 2007; Bassett and Bullmore, 2009; Siegel et al., 2012; Moghaddam and Wood, 2014). In this review, we highlight the role of information transmission from the medial orbitofrontal cortex (OFC), amygdala, and ventral tegmental area (VTA) to the ventral striatum (VS), in producing the pathologic repetitive behaviors and dysregulated affect observed in obsessive-compulsive disorder (OCD; Figure 1). We focus on this network because: (1) the VS is an interface between striatal and limbic circuitry, and thus is uniquely poised to process affective and behavioral selection information; (2) this network is likely to be complementary to dorsal striatal networks in the context of OCD models, and is therefore an important area of study; and (3) an incomplete understanding of the neural substrates of OCD and ineffective treatments suggest a more encompassing view of the disorder is necessary. Our central goal is to illustrate that the convergence of these inputs in the VS may underlie the role of the corticolimbic-VS network in producing repetitive behavioral selection in OCD. We suggest that the simplified framework proposed here can be used to understand the circuit mechanisms underlying OCD symptomatology.

\section{Clinical Features of Obsessive-Compulsive Disorder}

OCD affects $2-3 \%$ of the world's population, greatly diminishes quality of life, and is a leading cause of illness-related disability (Bystritsky et al., 2001; Milad and Rauch, 2012; Subramaniam et al., 2013; Pauls et al., 2014; Ahmari and Dougherty, 2015). OCD is a heterogeneous disorder, and the obsessive thoughts and accompanying compulsive behaviors that define OCD are often conceptualized as either four or five distinct symptom dimensions, that potentially map onto distinct neuronal substrates (Mataix-Cols et al., 2005; Pinto et al., 2007; American Psychiatric Association D-TF, 2013; Pauls et al., 2014). Examples of obsession-compulsion pairs in these categories include: (1) intrusive thoughts regarding harm or doubt, and compulsive checking behavior; (2) obsessions with symmetry, and compulsive ordering, counting, and repeating; (3) taboo obsessive thoughts, and compulsive neutralizing thoughts or behaviors; (4) obsessive thoughts about contamination and compulsive cleaning and sanitation; and (5) obsessive thoughts about hoarding paired with hoarding behavior. However, it should be noted that hoarding disorder is a separate diagnostic category in the most recent version of the Diagnostic and Statistical Manual
(DSM-5; Mataix-Cols et al., 2005; Pinto et al., 2007; American Psychiatric Association D-TF, 2013; Pauls et al., 2014). Although patients with OCD often have symptoms in multiple dimensions, and symptom content can fluctuate throughout the course of illness, obsessive thoughts, compulsive behaviors, and/or mental rituals are generally present in all OCD patients.

\section{Affective Dysregulation is a Critical Component of OCD Pathology}

Though the DSM-5 classifies OCD and related disorders as a separate entity, based on potential unique neurobiological substrates, it was originally categorized as an anxiety disorder in older versions of the DSM (Stein et al., 2010; American Psychiatric Association D-TF, 2013). How to classify OCD, and its relationship to other anxiety disorders, is a topic of ongoing debate in the field (Nutt and Malizia, 2006; Craig and Fineberg, 2008; Bienvenu et al., 2012). Regardless, it is clear from both clinical presentation and ongoing research that anxiety is an important component of the disorder. Patients with OCD compulsively engage in repetitive or ritualistic behavioral sequences, which are typically performed to alleviate or avoid the severe distress and anxiety that often accompanies obsessive thoughts (Stein et al., 2010; Milad and Rauch, 2012; de Haan et al., 2013; Pauls et al., 2014; Ahmari and Dougherty, 2015). High levels of anxiety, or even panic, may occur if compulsive behaviors cannot be executed (Nutt and Malizia, 2006; Stein et al., 2010). Thus, for many patients, anxiety links the two defining features of OCD: obsessions and compulsions.

The fact that anxiety typically serves as a key moderator of OCD symptoms underscores the fact that affective dysregulation is a critical component of OCD pathology. In keeping with this idea, deep brain stimulation targeting the nucleus accumbens (NAc) core has been found to improve both obsessivecompulsive symptoms and anxiety (Mantione et al., 2015). Additionally, cessation of NAc deep brain stimulation worsens scores on the Yale-Brown Obsessive Compulsive Scale (YBOCS) and the Hamilton Anxiety Rating Scale (HAM-A; de Koning et al., 2011; Ooms et al., 2014). Improvements in both obsessivecompulsive and affective symptoms by a single treatment suggest an underlying connection between affective dysregulation and OCD, strengthening the idea that emotional dysregulation is critical to promoting OCD symptoms. This is supported by epidemiological evidence showing that anxiety disorders, particularly social anxiety, panic disorder, and generalized anxiety disorder, have higher than chance levels of comorbidity in patients with OCD (Black et al., 1992; Nestadt et al., 2001; Bartz and Hollander, 2006; Murphy et al., 2013). Taken as a whole, these findings support the presence of convergent neuropathologies in anxiety and OCD (Nestadt et al., 2003), and suggest that it is critical to model both components of the disorder for a more accurate understanding of OCD pathophysiology. There is also substantial comorbidity between OCD and major depressive disorder (Nestadt et al., 2001, 2003; Denys et al., 2004c; Stein et al., 2010), further suggesting that the 
A

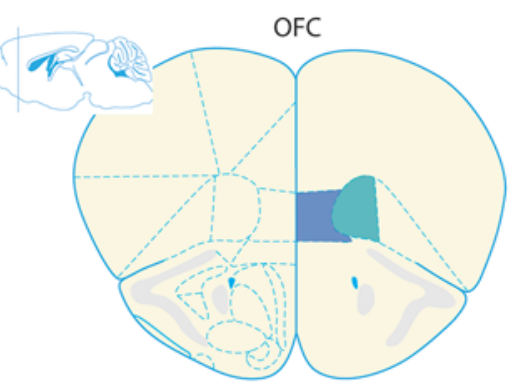

B

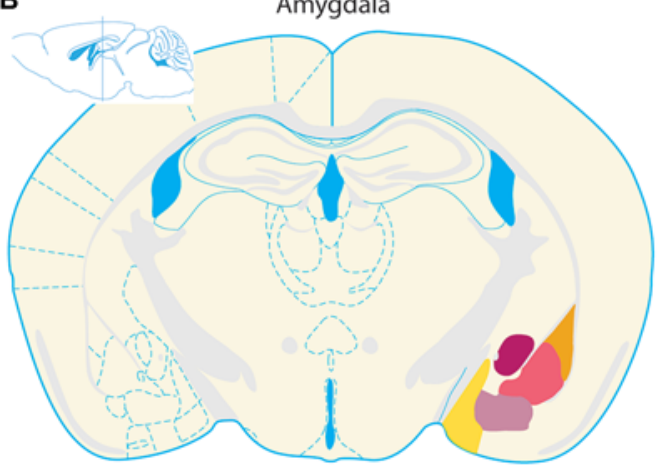

c

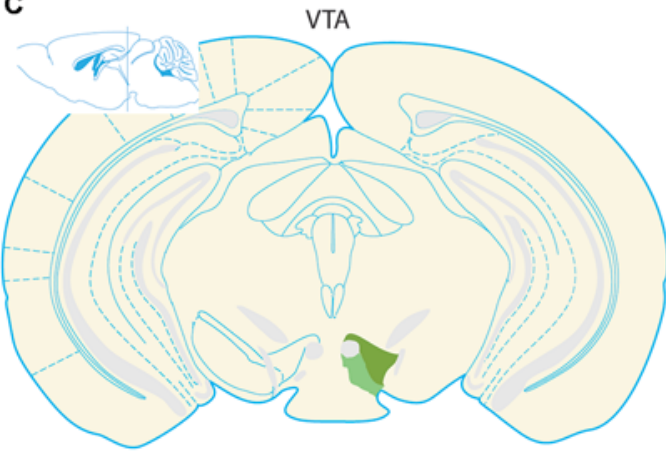

Medial OFC

Ventromedial OFC

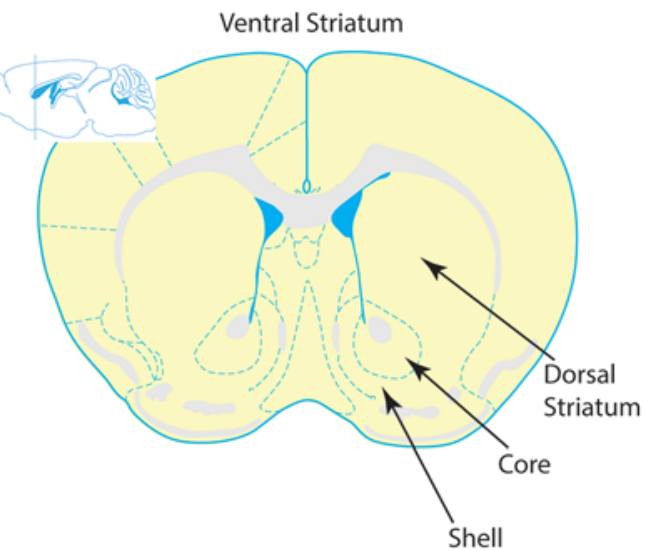

Lateral Amyg

Basolateral Amyg

Basomedial Amyg

Medial Amyg

Central Amyg

Parabrachial VTA

Paranigral VTA

FIGURE 1 | Organization of corticolimbic-ventral striatal network. Stylized coronal section schematics of the corticolimbic inputs to the ventral striatum (VS) are depicted alongside a schematic of the VS. Input regions are pictured in the left column, and coronal schematics are organized from top to bottom according to relative anterior to posterior locations. (A) Prefrontal section with the two regions comprising the medial OFC and ventromedial OFC-depicted in blue tones.

(B) Simplified depiction of the amygdala complex in orange and violet tones. The amygdala contains several nuclei, which follow numerous naming conventions. The left hemisphere contains a more detailed depiction of subregion outlines, and the right hemisphere highlights several nuclei. The lateral, basolateral (also known as basal nucleus), and basomedial (also known as accessory basal nucleus) nuclei collectively form the basolateral complex. The cortical nucleus is not depicted in this schematic. (C) The two largest nuclei of the VTA, the parabrachial and paranigral nuclei, are highlighted in green tones. Some definitions of the VTA also include midline nuclei not depicted, such as the interfascicular, rostral linear, and central linear nuclei. (D) The VS is depicted, with special emphasis on the NAc. The core and shell regions of the NAc are denoted with arrows and bounded by dashed lines. For reference, the dorsal striatum (caudate/putamen) is notated. All schematics adapted from the 3rd edition of The Mouse Brain, by Franklin and Paxinos (1997).

pathologic processes underlying OCD impact limbic circuitry. While obsessions and compulsions are not purely a product of emotional dysregulation, these observations support the notion that affective dysregulation-in particular pathologic anxiety-is of central importance to OCD.

\section{Corticolimbic-Ventral Striatal Models may Capture the Affective Components of OCD}

In this review we focus on the role that converging inputs from a corticolimbic network to the VS may play in producing compulsive behaviors in OCD, with several important caveats in mind: (1) No model is a complete account of a neuropsychiatric disorder, and a corticolimbic-VS explanation of OCD does not capture all features of the disorder; (2) OCD is a heterogeneous disorder. Different symptom clusters may be produced by different neuronal or circuit abnormalities, and future work should address how the data and ideas covered here can be applied to different subtypes of OCD; (3) We focus on VS circuitry, with the understanding that other brain regions, including dorsal striatum, are clearly important to the pathophysiology of OCD, and that circuits including dorsal 
and VS are likely to be cooperative, and not antagonistic (Insel and Winslow, 1992; Graybiel and Rauch, 2000; Milad and Rauch, 2012; Burguière et al., 2013, 2015; Gremel and Costa, 2013; Gillan and Robbins, 2014; Pauls et al., 2014). Despite these caveats, investigating corticolimbic-VS circuitry and developing more expansive OCD models that take limbic information processing into account (Milad and Rauch, 2012; de Haan et al., 2013; Ahmari and Dougherty, 2015) are likely to help elucidate the pathophysiologic processes leading to OCD.

\section{VENTRAL STRIATUM AS A CORTICOLIMBIC INTEGRATOR}

\section{Ventral Striatal Cell Types and Connectivity}

Over $90 \%$ of the neurons in the VS are medium spiny, $\gamma$ aminobutyric acid (GABA) projection neurons, and several types of interneurons comprise the remaining population (Kawaguchi et al., 1995; Kawaguchi, 1997; Meredith, 1999; Nicola et al., 2000; Kreitzer, 2009; Gerfen and Surmeier, 2011; Gittis and Kreitzer, 2012). Medium spiny neurons (also known as spiny projection neurons) are the main output neurons of the striatum, and reside in an intermingled pair of compartments, known as patch and matrix. These compartments are identified by distinct immunoreactivity and gene expression patterns, and medium spiny neurons tend to have dendritic arbors that are confined to their respective patch or matrix compartments (Graybiel and Ragsdale, 1978; Crittenden and Graybiel, 2011). These data suggest striatum follows complex organizational principles that are critical to understanding the function of this system. Striatal interneurons (fast-spiking parvalbumin positive, low-threshold spiking, calretinin positive, and cholinergic tonically active neurons) can powerfully influence the function of spiny projection neurons (Graybiel and Ragsdale, 1978; Kawaguchi et al., 1995; Kawaguchi, 1997; Tepper and Bolam, 2004; Humphries and Prescott, 2010; Crittenden and Graybiel, 2011). Some of these interneuron subtypes have been linked to OCD (Burguière et al., 2013) and Tourette's syndrome (Xu et al., 2015) pathophysiology.

\section{Critical Features of VS Circuitry}

The VS contains, and is often synonymous in the literature with, the NAc core and the NAc shell. Subsets of NAc core projection neurons may form direct and indirect pathways homologous to those seen in dorsal striatum, which have classically been thought to promote or suppress movements, respectively (Albin et al., 1989). However, it remains unclear how well this model applies to VS projections (Sesack and Grace, 2010; Kupchik et al., 2015). The NAc core direct pathway is formed by medium spiny neurons that predominantly express D1 dopamine receptors, and projects to the substantia nigra pars reticulata and VTA; the indirect pathway contains medium spiny neurons expressing D2 receptors, and projects to the ventral pallidum and subthalamic nucleus (Albin et al., 1989; Zahm and Brog, 1992; Graybiel, 2000; Zhou et al., 2003; Humphries and Prescott, 2010; Kravitz et al., 2010; Sesack and Grace, 2010; Freeze et al., 2013). It is more difficult to extrapolate the direct and indirect pathway model to the NAc shell, though some authors have argued that connections with regions not traditionally included in the classic pathways form direct and indirect pathways (O'Donnell et al., 1997; Nicola et al., 2000; Sesack and Grace, 2010; Kravitz and Kreitzer, 2012). As an alternative to conceptualizing the shell within the direct/indirect pathway framework, it can also be thought of as an extension of the amygdala complex on the basis of intermingled and overlapping projection targets, as well as cytoarchitecture (Zahm and Brog, 1992; Sesack and Grace, 2010; Zorrilla and Koob, 2013). Therefore, the NAc shell region is also part of a larger limbic network. Taken together, the connectivity of the NAc core and shell place the VS in a key position to integrate behavioral selection and affective information processing (Kelley, 2004; Balleine and O'Doherty, 2010; Volman et al., 2013).

Among the VS neurons that project to dopamine neurons, NAc shell neurons preferentially innervate dopamine neurons in the VTA, while NAc core neurons tend to innervate dopamine neurons in substantia nigra (Sesack and Grace, 2010). Subsets of substantia nigra and VTA dopamine neurons project to striatal subregions more dorsal to the striatal subregions they receive projections from Haber et al. (2000); Joel and Weiner (2000). This leads to a flow of information from ventral to dorsal striatal circuits via communication with dopamine neurons, and enables information processed within the VS to iteratively influence dorsal striatal computations (Figure 2).

\section{Corticolimbic Inputs Converge in Ventral Striatum}

The VS inputs detailed in this review, transmit diverse information (Zorrilla and Koob, 2013), and the capacity of VS to integrate disparate information content is a defining feature of the region. Multiple cortical (Finch, 1996; Sesack and Grace, 2010) and amygdala (McGinty and Grace, 2009) inputs converge onto the same NAc neurons. In fact, up to 5-way convergence between afferent inputs to the VS can be demonstrated on single NAc neurons (Finch, 1996). Additional studies demonstrate basolateral amygdala and subiculum (French and Totterdell, 2003), and medial prefrontal cortex and subiculum (French and Totterdell, 2002), synaptic inputs on the same NAc neuron. Furthermore, NAc excitatory post-synaptic potentials evoked by basolateral amygdala stimulation are blocked by D1 dopamine receptor activation (Charara and Grace, 2003), suggesting that VS is an interface between dopamine and amygdala systems. Projections from the mOFC also terminate in the same VS regions as projections from VTA and the basolateral amygdala (Kelley et al., 1982; Ongur and Price, 2000; Voorn et al., 2004; Whiteside et al., 2004), though it is important to note that there is less direct evidence of convergence between amygdala and OFC inputs onto single NAc neurons. Because it is suggested that activation of NAc projection neurons is likely driven by nearly simultaneous coactivation of multiple inputs (Pennartz et al., 1994), converging inputs from these regions are likely to be essential for the VS 
to function as a limbic-behavioral interface (Mogenson et al., 1980).

\section{Converging Information in Ventral Striatum could Lead to OCD Symptomatology}

By integrating several modalities of limbic information into striatal circuitry, the VS is a strong candidate for selection and promotion of compulsive behaviors in OCD patients. In support of this notion, the rodent VS has long been implicated in aspects of behavior that may play a role in, or reflect, compulsivity. These include reward, effort, cue-driven behavior, conditioning, and drug seeking (Parkinson et al., 1999; Robbins and Everitt, 2002; Salamone and Correa, 2002; Wise, 2004; Kalivas et al.,

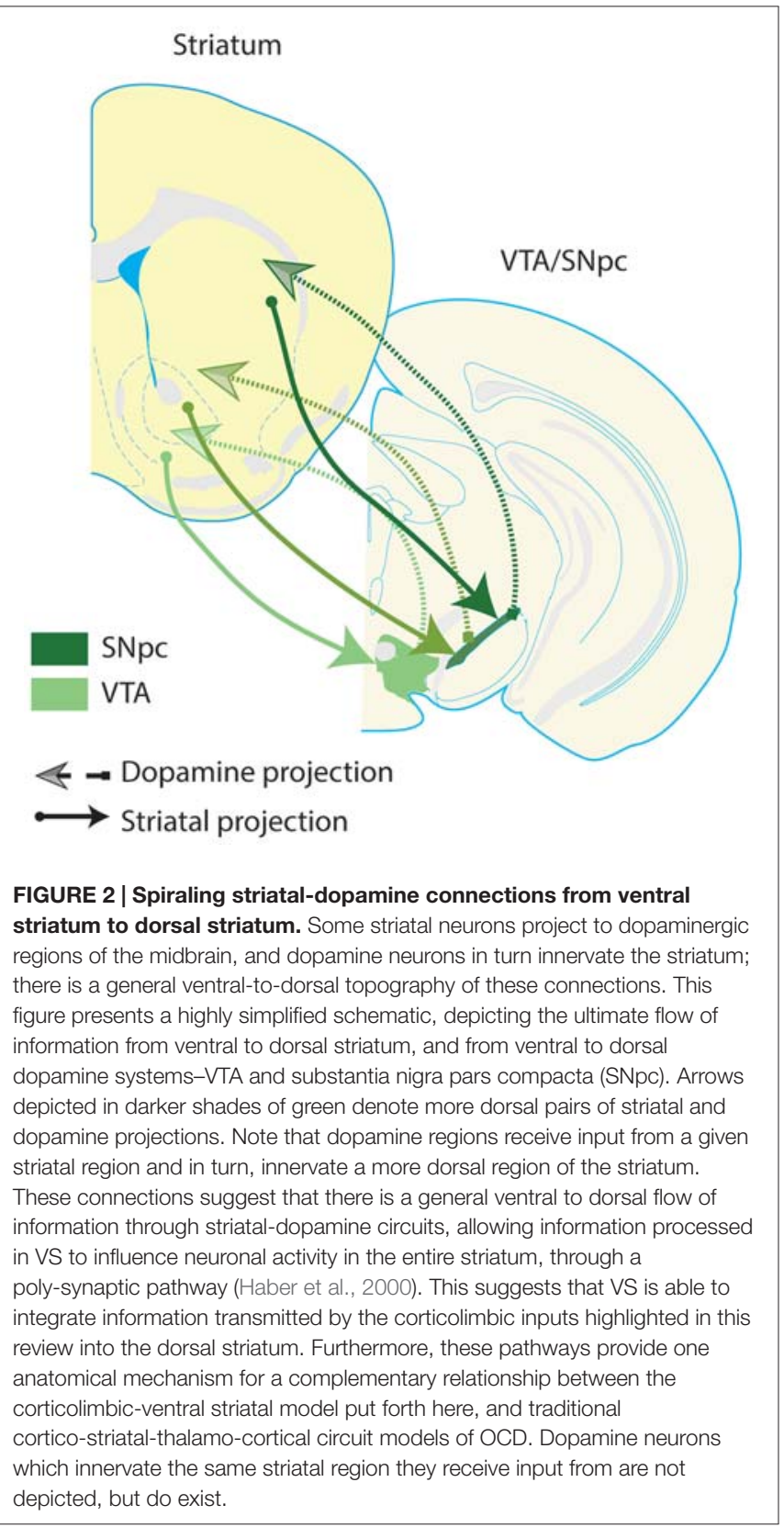

2005; Ikemoto, 2007; Yin et al., 2008; Carlezon and Thomas, 2009; Russo et al., 2010; Volman et al., 2013). Thus, a strong line of prior research suggests corticolimbic-VS networks may contribute to OCD symptomatology.

\section{AMYGDALA SIGNALING IN THE VENTRAL STRIATUM}

\section{Amygdala-Ventral Striatum Circuit Anatomy}

The amygdala complex consists of several subregions, including the cortico-medial region (cortical, medial, and central nuclei), and basolateral region (Pitkänen et al., 1997; LeDoux, 2000). The basolateral region is often further subdivided according to several schemes, into lateral, basal, and accessory basal nuclei, or into lateral, basolateral, and basomedial nuclei. The basolateral subregion of the amygdala issues a dense glutamatergic projection to the VS. This projection is roughly topographical, such that rostral regions project to lateral VS (preferentially to NAc core), and caudal regions project more medially (preferentially to NAc shell; Kelley et al., 1982; Wright et al., 1996; Pitkänen et al., 1997; LeDoux, 2000; Voorn et al., 2004; Sesack and Grace, 2010; Janak and Tye, 2015). Projections from the basolateral amygdala to the NAc core also tend to follow compartmental boundaries (Figure 3). Specifically, basal nucleus projections largely terminate in NAc core patches (Wright et al., 1996). Since dopaminergic neurons preferentially receive input from medium spiny neurons that are located in the patch compartments, including those dopamine neurons projecting to more dorsal segments of the striatum (Berendse et al., 1992; Wright et al., 1996; Crittenden and Graybiel, 2011), basal amygdala inputs to the NAc core could influence information processing throughout the entire striatum and dopamine system. In contrast, amygdala accessory basal nucleus projections preferentially terminate in the matrix compartments of the core (Wright et al., 1996). Many NAc core matrix neurons project to the substantia nigra pars reticulata, an output nucleus of the basal ganglia, and therefore could contribute directly to behavioral selection (Berendse et al., 1992; Wright et al., 1996). Thus, the VS serves as a region in which limbic information from the amygdala can directly impact behavior and modulate the flow of information throughout the entire striatum.

\section{Amygdala Processes Multiple Forms of Affective Information}

The amygdala facilitates appropriate behavioral responses to aversive or harmful stimuli (Davis, 1992; LeDoux, 2000), and has classically been associated with fear (also conceptualized as threat) conditioning and extinction (LeDoux, 2000, 2007, 2014). According to simplified models of fear/threat conditioning in rodents, multimodal, threat-related, sensory information from cortical and thalamic projections is transmitted directly to the lateral nucleus of the amygdala (LeDoux et al., 1990), and is subsequently transferred to other basolateral nuclei. Information then flows from the 

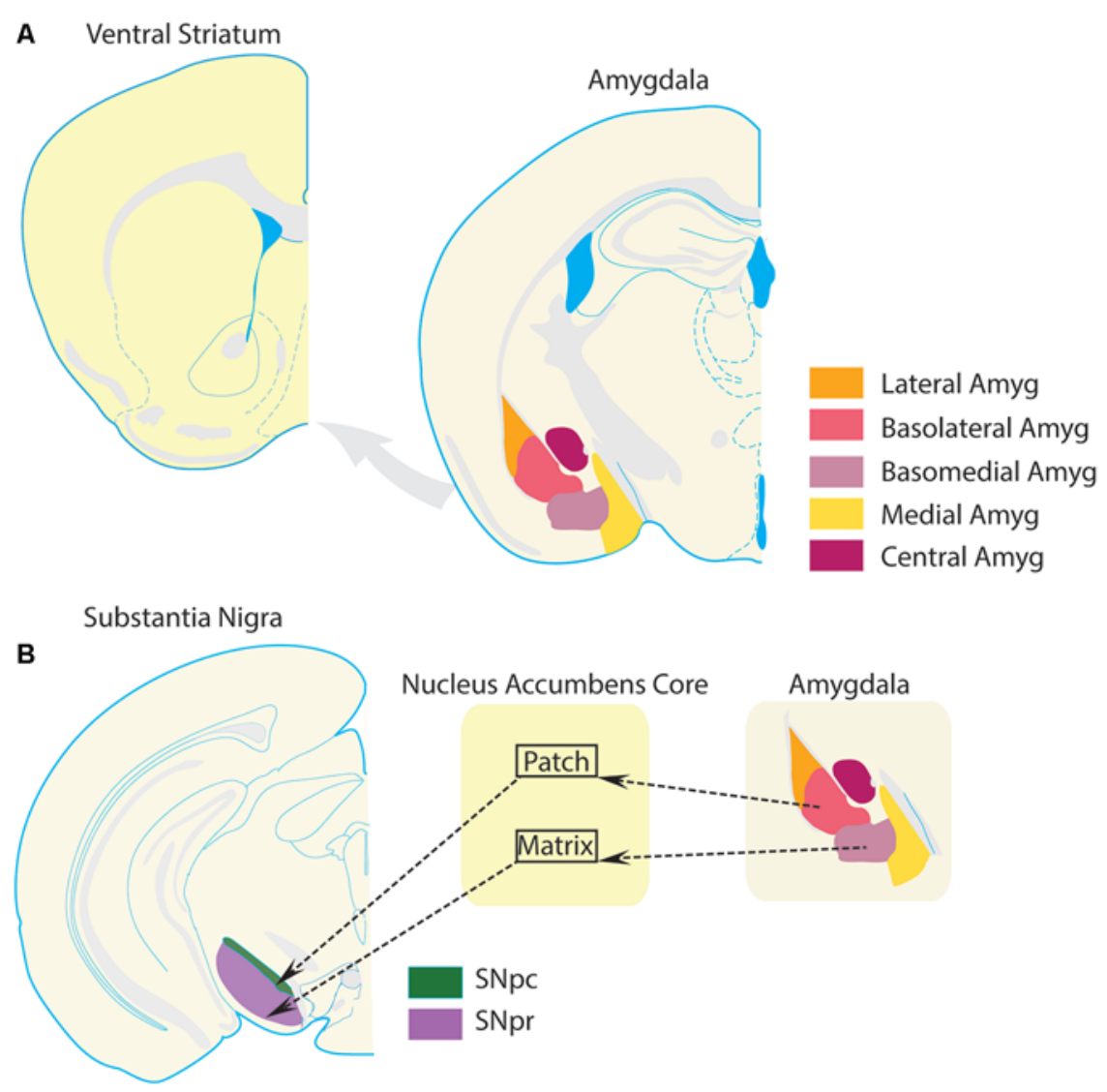

FIGURE 3 | Amygdala projections to ventral striatum. The VS receives a glutamatergic projection from the basolateral amygdala complex. (A) Schematics of VS and amygdala following the same conventions as Figure $\mathbf{1}$ are presented for clarity. (B) Substantia nigra par compacta (SNpc), which receives input from projection neurons in the patch compartments of the NAc core, sends a large number of dopamine projections to the dorsal striatum. The substantia nigra pars reticulata (SNpr), which is part of the traditional striatal direct pathway and promotes selection of behaviors, is preferentially innervated by projection neurons in the matrix compartments of the NAc core. This compartmental segregation of NAc-SN projections is followed by the basolateral amygdala complex as well. Projections from the basolateral nucleus terminate preferentially in the patch compartments of NAc, while projections from the basomedial nucleus terminate preferentially in the matrix compartments of the NAc. Thus, a basolateral nucleus-NAc core patch- SNpc circuit could regulate dopamine transmission in the striatum. On the other hand, a basomedial-NAc core matrix-SNpr circuit could modulate information transmission in the direct pathway. Thus, these circuits provide a theoretical foundation for amygdala-VS circuits to modulate behavioral selection and striatal processing. Dysregulation of this circuit in OCD could potentially contribute to compulsive behavior.

basolateral nuclei to the central nucleus of the amygdala, which functions as an output to numerous brain regions (LeDoux, 2007; Janak and Tye, 2015). Lesions of the basolateral amygdala disrupt acquisition of conditioned fear (Nader et al., 2001), and central amygdala is commonly associated with expression of conditioned fear (Hitchcock and Davis, 1986). Therefore, the amygdala is critical for threat learning and promoting behaviors driven by fearful situations (LeDoux, 2014).

In addition to a role in fear and threat conditioning, the amygdala also regulates anxiety. The activity of basolateral amygdala networks reflects the anxiogenic potential of the environment, and points to a role for this subregion in processing anxiety-related information (Likhtik et al., 2014). Recent reports also suggest that subsets of intra-amygdala projections bidirectionally modulate anxiety-like behavior (Tye et al., 2011; Janak and Tye, 2015). Finally, the basolateral amygdala also contributes to anxiogenic effects through connections with the ventral hippocampus (Felix-Ortiz et al., 2013). These findings detail some of the circuits of the basolateral amygdala that contribute to anxiety-related behaviors. Though these projections have not been fully mapped, and their effects on information processing in VS are not completely understood, it is clear that interconnected basolateral amygdala networks modulate anxiogenic and anxiolytic states. These same networks could convey anxiety-related information to VS, which could directly impact behavioral selection and reinforcement processes important to OCD.

Early amygdala lesion studies suggested that amygdala is involved in numerous aspects of cognition, and is not limited to processing aversive information (Zorrilla and Koob, 2013; Janak and Tye, 2015). Specifically, basolateral amygdala, and its projections to the VS, are necessary for some forms of reward-related Pavlovian and instrumental 
behavior (Cador et al., 1989; Everitt et al., 1989; Hiroi and White, 1991; Hatfield et al., 1996; Setlow et al., 2002; Stuber et al., 2011), and neurons in the basolateral amygdala also respond to rewarding stimuli (Schoenbaum et al., 1999; Paton et al., 2006; Morrison and Salzman, 2010), indicating that the same regions that drive fear learning also contribute to appetitive learning. A growing appreciation for the complexity of the amygdala complex has resulted in a more nuanced understanding of this region's role in fear learning, appetitive learning, and value encoding (Janak and Tye, 2015), and it is clear that the amygdala promotes adaptive behavioral responses to both positive and negative environmental stimuli.

\section{Dysregulation of Emotional Information Processing in Amygdala could Contribute to Compulsivity}

By transmitting information related to anxiety, fear, and reward to the VS, the amygdala regulates how affect and motivation influence adaptive behavior. As mentioned above, compulsivity is often driven by anxiety, threat avoidance, or aberrant motivation in OCD patients (Milad and Rauch, 2012; Pauls et al., 2014; Ahmari and Dougherty, 2015). Since the amygdala is central to processing these forms of information (Janak and Tye, 2015), aberrant communication of anxiety-related information from amygdala to VS could mediate anxiety-driven compulsive behavior. Likewise, active threat avoidance behavior requires intact basolateral amygdala and VS (BravoRivera et al., 2014), suggesting that activity in this circuit could lead to excessive avoidance behavior in OCD. Collectively, this suggests that amygdala is central to multiple aspects of cognition that are impaired in OCD, and that amygdala dysregulation may contribute to compulsivity by imparting excessive affective influence on behavioral selection.

In support of this theory (though less commonly highlighted in the literature), structural and functional amygdala abnormalities are associated with OCD. For instance, decreased amygdala volume has been shown in OCD patients (Szeszko et al., 1999; Pujol et al., 2004). Functional imaging studies have also suggested that amygdala representations of neutral or positive valences may be blunted in OCD. Specifically, when OCD patients view neutral faces (Cannistraro et al., 2004; Britton et al., 2010) or are anticipating rewards (Marsh et al., 2015), amygdala is hypoactive compared to controls (but see Simon et al., 2014). In contrast, amygdala is hyperactive in patients viewing images of fearful expressions; the degree of activation is correlated with symptom severity (Via et al., 2014). Likewise, threatening stimuli (Admon et al., 2012), and symptom provoking stimuli (Breiter et al., 1996; Mataix-Cols et al., 2004; van den Heuvel et al., 2004; Simon et al., 2010, 2014; Milad and Rauch, 2012) overactivate the amygdala of OCD patients. It should be noted, however, that these findings have not been uniformly replicated (Cannistraro et al., 2004). While it is unclear what underlies these discrepancies in the literature, a substantial amount of data suggest that threatening, fearful, and symptom provoking stimuli are over-represented in amygdala in OCD.

All told, these data suggest that the amygdala can be either hyperactive or hypoactive in patients with OCD. This could lead to low signal-to-noise representations of neutral or positive affective information. In other settings, such as during symptom provocation or when dealing with threatening stimuli, amygdala could be overactive and produce excessive emotional processing in VS. These disruptions could lead to weakened representations of neutral stimuli (for example, items in a room), but excessively strong representations of symptom provoking stimuli (for example, a trashcan or a messy bathroom). The effect of this imbalance in representational strength could ultimately lead to selection of behaviors in striatal circuits on the basis of disproportionately strong emotional representations. In this example, the sight of a trashcan or bathroom mess could provoke cleaning and sanitation compulsions. Thus, through connections with the VS, the amygdala may play a critical role in OCD symptoms.

\section{VENTRAL TEGMENTAL AREA SIGNALING IN THE VENTRAL STRIATUM}

\section{Ventral Tegmental Area Anatomy}

Preclinical anatomical studies indicate that the VTA is a functionally and anatomically heterogeneous structure which contains a pair of major nuclei, the parabrachial and paranigral, and is often described as containing several smaller nuclei, including the central linear, rostral linear, and interfasicular nuclei (Oades and Halliday, 1987; Ikemoto, 2007; SanchezCatalan et al., 2014). Approximately two thirds of the neurons in the VTA are dopaminergic, and the majority of the remaining neurons are GABAergic (Swanson, 1982; Nair-Roberts et al., 2008; Sesack and Grace, 2010). While there are local GABAergic connections in the VTA, many VTA GABA neurons are projection neurons (Van Bockstaele and Pickel, 1995; Carr and Sesack, 2000; Omelchenko and Sesack, 2009). In recent years, it has come to light that VTA also contains a sizeable population of neurons that release glutamate, and that dopamine neurons can co-release glutamate and GABA (Yamaguchi et al., 2007, 2011; Hnasko et al., 2010; Stuber et al., 2010; Tritsch et al., 2012). Thus, the VTA projects a chemically diverse signal to regions such as the prefrontal cortex, amygdala, and VS (Swanson, 1982; Van Bockstaele and Pickel, 1995; Carr and Sesack, 2000). The various VTA projections are intermingled and have differing electrophysiological properties and protein expression patterns, largely along a mediolateral gradient (Lammel et al., 2008, 2014; Volman et al., 2013). These anatomical characteristics enable the VTA to subserve a diverse assortment of cognitive functions in downstream brain regions. 


\section{Dopaminergic Signaling in Ventral Striatum Directly Contributes to Behavioral Selection}

The VS receives a dense dopaminergic projection from the VTA, and a much less studied GABAergic projection (Swanson, 1982). The firing patterns of dopamine neurons, including those projecting to the VS, encode errors in the predicted value of rewards (Ljungberg et al., 1992; Schultz et al., 1993, 1997; Montague et al., 1996; Schultz, 1998). This signal establishes learned associations and guides behavioral selection (Houk et al., 1995; Montague et al., 1996; Schultz et al., 1997; Schultz, 1998; Waelti et al., 2001; Joel et al., 2002; Morris et al., 2006; Roesch et al., 2007; Glimcher, 2011). Moreover, this projection subserves various aspects of reinforcement and motivation (Schultz, 1998; Wise, 2004; Salamone et al., 2007). Thus, VTA innervation of VS strongly modulates and sustains behavioral output.

Dopamine is released in the VS in response to rewarding or reward-predictive stimuli, including food and drugs of abuse (Phillips et al., 2003; Roitman et al., 2004, 2008; Stuber et al., 2005; Brown et al., 2011; McCutcheon et al., 2012), and often decreases the activity of VS medium spiny neurons (Peoples and West, 1996; Cheer et al., 2005; Roitman et al., 2005; Wheeler and Carelli, 2009). Some studies, however, have reported that subsets of VS projection neurons are also activated by aversive stimuli (Setlow et al., 2003; Roitman et al., 2005; Kravitz and Kreitzer, 2012), which highlights the heterogeneity of striatal representations. Taken together, these data suggest that the activity of VS medium spiny neurons is strongly modulated by dopaminergic input, which contributes to behavioral selection and value representation.

\section{Multiple Lines of Clinical Evidence Suggest that OCD is Characterized by a Hyperdopaminergic State}

There are several lines of evidence for dopamine system pathology in OCD patients. Several studies have reported reduced D1 and D2 dopamine receptor binding in striatum (Denys et al., 2004b; Hesse et al., 2005; Nikolaus et al., 2010; Klanker et al., 2013), including in the VS (Figee et al., 2014), which is hypothesized to be a compensatory response to increased dopaminergic tone (Klanker et al., 2013). These findings go hand-in-hand with several pharmacological findings. For instance, cocaine, amphetamine, and methylphenidate, which are indirect dopamine agonists, can induce or exacerbate OCD symptoms (Denys et al., 2004a). When dopamine antagonists are used to augment selective serotonin reuptake inhibitors, symptom improvement is sometimes observed; this is especially the case in patients with comorbid tic disorder (McDougle et al., 2000; Denys et al., 2004a; Klanker et al., 2013). Thus, abnormalities in the dopamine system could account for some of the dysfunction observed in OCD.

Abnormalities in the gene encoding catechol-o-methyltransferase (COMT), which metabolically terminates dopamine signaling following neurotransmitter release, also suggest that dopamine signaling may be disrupted in patients with OCD.
A functional allele of COMT that is linked to decreased metabolism of dopamine is associated with susceptibility to OCD (Karayiorgou et al., 1997, 1999; Alsobrook et al., 2002). Additionally, there are significant differences between distributions of COMT high activity homozygotes, low activity homozygotes, and heterozygotes in OCD patient and control populations (Schindler et al., 2000; Niehaus et al., 2001). It should also be noted that several studies have found no association between this COMT allele and OCD patients (Denys et al., 2004a); however, the limited evidence available suggests that COMT could be hypofunctional in OCD, and may ultimately lead to hyperdopaminergic signaling (Denys et al., 2004a; Klanker et al., 2013).

While a substantial proportion of the available evidence suggests that OCD is associated with a hyperdopaminergic state, there are also findings that are generally suggestive of a more complex relationship between OCD symptomatology and dopamine. For instance, in spite of the above findings suggesting that excessive dopamine signaling may contribute to pathology in OCD, there is: (1) evidence that dopamine antagonism can also exacerbate symptoms or fail to produce a clinical benefit (Denys et al., 2004a; Klanker et al., 2013; Simpson et al., 2013); and (2) imaging data suggesting both increased and decreased dopamine transporter binding (Denys et al., 2004a; van der Wee et al., 2004; Hesse et al., 2005; Klanker et al., 2013). These inconsistencies suggest that unidirectional disruptions of dopaminergic signaling may not provide a straightforward explanatory model of OCD. We therefore theorize that OCD may be associated with a trend towards excessive dopaminergic signaling, with the understanding that this literature is evolving, and must account for some inconsistencies moving forward.

\section{Relationship between Dopamine Signaling and Repetitive Behaviors in Animal Models}

One approach to clarifying the role of dopamine signaling in OCD is to employ animal models and systematically probe the function of the dopamine system. There is clear evidence that modulating dopamine signaling in the striatum leads to abnormal repetitive behaviors in animals. Knockdown of the dopamine transporter leads to excessive grooming in rodents (Berridge et al., 2005), and D1 agonists and partial agonists also produce a similar effect (Molloy and Waddington, 1987; White et al., 1988). Likewise, when amphetamine is injected directly into the VS, it produces stereotyped and repetitive behaviors (Colle and Wise, 1991). Quinpirole, a D2/D3 dopamine receptor agonist, has also been used to model compulsive behaviors associated with OCD, and electrical stimulation of the VS alleviates the increased frequency of these abnormal behaviors (Einat and Szechtman, 1995; Joel, 2006; Mundt et al., 2009). Thus, dopaminergic manipulations produce repetitive behaviors that may be used to model some aspects of compulsivity in OCD patients. While these manipulations do not reproduce all aspects of the disorder, they are important tools for understanding the neuronal 
underpinnings of some of the behavioral symptoms seen in OCD.

All told, dopaminergic inputs to the VS likely contribute to selecting and sustaining appropriate behavioral sequences, in part through representations of action value and through reinforcement processes. A hyperdopaminergic state, however, could lead to excessive valuation of a behavior, or repetitive selection of a behavior. With this in mind, dopamine signaling in the VS is well positioned to directly contribute to OCD-related compulsivity. VTA projections to the VS may be particularly relevant to OCD because this pathway is classically associated with producing and sustaining effortful behaviors, mediating locomotor arousal, and energizing behavioral responses (Salamone and Correa, 2002; Wise, 2004; Salamone et al., 2007). Thus, through several mechanisms, dysregulation of this circuitry could contribute to compulsive behavior.

\section{ORBITOFRONTAL CORTEX SIGNALING IN THE VENTRAL STRIATUM}

\section{Orbitofrontal Cortex Projections}

The OFC receives a wide variety of inputs from sensory structures, the subiculum, entorhinal cortex, and amygdala, so that the external world is richly represented and integrated with contextual, limbic, and sensory information (Krettek and Price, 1977; Groenewegen et al., 1997; Ongur and Price, 2000). Rodent prefrontal regions are identified on the basis of thalamic projections (Rose and Woolsey, 1948; Leonard, 1969; Uylings et al., 2003). Thus, the lateral orbitofrontal, ventrolateral orbitofrontal, and agranular insular cortices are all considered lateral OFC (Ongur and Price, 2000; Zald and Rauch, 2006; Price, 2007), while the medial OFC and ventromedial OFC comprise the mOFC. It is important to clarify that the term "medial OFC" can be used to refer to a specific subregion in the prefrontal cortex, or can refer to the pair of aforementioned regions. Throughout this review the term is used in the latter sense. Based on connectivity, the mOFC regions bear a stronger resemblance to other medial prefrontal cortex regions, such as infralimbic and prelimbic cortex, than to the lateral OFC (Zald and Rauch, 2006; Price, 2007). Specifically, the mOFC preferentially innervates the VS, while lateral OFC innervates more dorsal components, particularly the centromedial striatum (Ongur and Price, 2000; Price, 2007; Schilman et al., 2008; Hoover and Vertes, 2011; RodriguezRomaguera et al., 2015). The striatal projection patterns of lateral OFC and mOFC thus implicate these structures in distinct cognitive operations.

\section{Medial Orbitofrontal Cortex Regulates Behavioral Selection and Value-Based Information Processing}

The mOFC is closely linked to outcome-based behavioral selection. A thorough meta-analysis of 87 functional imaging studies in humans revealed an association between mOFC activation and positive valence stimuli, such as reward (Kringelbach and Rolls, 2004). This region is also implicated in evaluating and choosing between actions, as demonstrated by the fact that mOFC lesions impair the ability of nonhuman primates to select the most advantageous option when comparing differently-valued outcomes (Rudebeck and Murray, 2011; Milad and Rauch, 2012; Noonan et al., 2012). Further implicating $\mathrm{mOFC}$ in choosing between behavioral options are lesion studies in rodents which demonstrate excessive risky behavioral choices (Stopper et al., 2014). Finally, in support of the idea that mOFC encodes information governing behavioral selection, a meta-analysis of human imaging studies suggests that $\mathrm{mOFC}$ represents a common neuronal currency for rewards and punishments, so that different modalities of value are encoded in the same networks (Levy and Glimcher, 2012). These observations suggest that mOFC could subserve decision making by integrating information about the outcomes that could result from an animal's competing behavioral options (Rudebeck and Murray, 2014). Congruent with this view, mOFC has been implicated in selecting and adapting goal-directed behaviors and transforming value representations into behavior (Hollerman et al., 2000; Balleine and O'Doherty, 2010; Gourley et al., 2010). Thus, mOFC dysregulation could contribute to OCD symptoms by encoding aberrant representations of value comparisons between behaviors, leading patients with OCD to engage in compulsive behaviors despite negative consequences.

\section{Medial OFC is Structurally and Functionally Altered in OCD}

Before discussing OFC abnormalities in OCD patients, it is important to note that some studies do not clearly differentiate between medial and lateral OFC, and thus focusing exclusively on $\mathrm{mOFC}$ in the human imaging literature can be challenging. OCD is generally associated with hyperactivity in OFC (Saxena et al., 2001; Whiteside et al., 2004), and a meta-analysis of imaging studies confirmed that abnormalities in OFC activity are consistently observed in OCD patients (Menzies et al., 2008). Early functional imaging studies reported increased activity in bilateral OFC (Alptekin et al., 2001), left OFC (Swedo et al., 1989), and orbital gyrus (Baxter et al., 1988) of OCD patients at rest; the magnitude of OFC metabolic activation was correlated with clinical ratings of symptom severity (Swedo et al., 1989). Supporting suggestions that OFC hyperactivity may lead to obsessions and compulsions, symptom provocation in OCD patients increases bilateral OFC metabolic activity (Rauch et al., 1994). Furthermore, left OFC activity is increased relative to resting state when OCD patients, but not healthy controls, are exposed to stimuli designed to evoke feelings of disgust (Stein et al., 2006). Thus, most evidence suggests that increased OFC activity is a component of OCD pathophysiology (Saxena et al., 2001). In support of this idea, selective serotonin reuptake inhibitors, which are first-line treatments for OCD, decrease OFC metabolic activity; activity in both lateral and mOFC is more strongly reduced in treatment responsive patients than non-responsive patients (Swedo et al., 1992; Saxena et al., 1999, 2002). 
However, hyperactivity in the OFC of OCD patients has not been uniformly reported. Functional imaging studies have reported decreased OFC metabolic activity during several cognitive tasks. For example, during a stop signal task, which measures inhibitory control, adolescents with OCD show decreased metabolic activity in right OFC vs. healthy controls (Woolley et al., 2008). During reversal learning tasks, metabolic activity in lateral OFC and mOFC is also reduced in patients with OCD and their family members, but not healthy controls (Remijnse et al., 2006; Chamberlain et al., 2008). Further mechanistic studies in both humans and animals are needed to relate hyperactivity at rest and during symptom provocation (Insel and Winslow, 1992; Saxena et al., 2001; Nakao et al., 2005; Milad and Rauch, 2012; Ahmari and Dougherty, 2015) with these reports of hypoactivation during cognitive tasks. One potential explanation is that OFC representations may have decreased signal-to-noise ratios in OCD patients (greater activity levels at baseline and blunted activation when the region is engaged). This could ultimately lead to improper value-based behavioral selection, and potentially contribute to the symptoms manifested in OCD.

OCD is also generally associated with structural OFC abnormalities-specifically decreased OFC volume, including in mOFC, compared to healthy controls (Szeszko et al., 1999; Pujol et al., 2004; Rotge et al., 2009). Furthermore, treatment-refractory patients have decreased OFC volume compared to treatmentresponsive cases (Atmaca et al., 2006). These findings, however, have not been uniformly replicated (Kim et al., 2001); several factors may underlie this contradiction (for further details, see Ahmari, 2015). Because this review focuses on interregional communication with the VS, reports of increased structural and functional connectivity between mOFC and VS are of particular interest (Sakai et al., 2011; Nakamae et al., 2014). This increased connectivity significantly predicts YBOCS score (Harrison et al., 2009), strongly suggesting a relationship between signaling in these regions and OCD symptoms. However, care must be taken interpreting these results, as a recent study found a significant negative correlation between VS and mOFC connectivity and YBOCS score (Posner et al., 2014). In total, these findings suggest that patients with OCD have both aberrant OFC activity and altered anatomy and connectivity with other brain regions.

These data support the idea that OFC dysregulation may produce abnormal repetitive behaviors, in part through mOFC signaling in the VS. Potential mechanisms include aberrant processing within mOFC leading to corrupted representations of value related information, which the VS utilizes for action selection. A second complementary idea is that mOFC activity in OCD patients could preferentially drive direct pathway VS neurons, ultimately leading to aberrant and repetitive behavioral output (Pauls et al., 2014). Although OFC control over striatal production of compulsive behaviors is classically associated with dorsal regions of the striatum (Fineberg et al., 2010; Albelda and Joel, 2012), the data summarized above suggest a more complex view, by strongly implicating the mOFC and its VS connections in the production of OCD symptoms.

\section{CORTICOLIMBIC-VENTRAL STRIATUM NETWORKS INVOLVED IN THE PRODUCTION OF COMPULSIVE BEHAVIORS}

In the final section of this review, we will discuss the role of corticolimbic-VS networks in instrumental and Pavlovian behaviors, and explore the relationship of these behaviors to OCD. We then theorize how dysfunction in this network could contribute to compulsive behaviors in OCD. Last, we discuss how the VS may be both a locus of pathology and site of effective intervention in OCD.

\section{Goal-Directed, Habitual, and Pavlovian Behaviors}

Behaviors can be classified according to the relationship between an action and the resulting outcome of that action. Instrumental behaviors, which require execution of an action in order to earn an outcome, can be either goal-directed or habitual. Goaldirected behaviors are those that are selected according to a representation of the contingency (the causal relationship) between the action and the resulting outcome, and the value of the outcome. An animal will stop selecting a goal-directed behavior if the outcome is devalued, or if the contingency between the action and outcome is degraded. In contrast, habitual behaviors are highly automatized behaviors that are triggered by stimuli in the environment, despite devaluation of the outcome, or degradation of the contingency between actions and outcomes (Balleine and Dickinson, 1998; Daw et al., 2005; Yin et al., 2008; de Wit and Dickinson, 2009). Pavlovian behaviors are elicited by a stimulus predicting an outcome; the animal's performance of the behavior does not cause outcome delivery (Balleine and Dickinson, 1998; Yin et al., 2008; de Wit and Dickinson, 2009). Distinct neural mechanisms may contribute to these three forms of behavioral selection.

\section{Compulsive Behaviors in OCD may be Mediated by Several Selection Mechanisms}

Compulsive behaviors in OCD are an example of how neuropathological processes can subvert behavioral selection, and how dysregulation of behavioral selection may contribute to debilitating symptomatology. The specific mechanisms involved are an open question, as it is unknown to what extent compulsive behaviors in OCD are selected by habit-like mechanisms (Graybiel and Rauch, 2000; Gillan and Robbins, 2014; Burguière et al., 2015), goal-directed mechanisms (McFall and Wollersheim, 1979; Rachman, 1997), or both (Piantadosi and Ahmari, 2015). Several lines of evidence also suggest that Pavlovian processes may contribute to OCD symptomatology (Milad et al., 2013; McLaughlin et al., 2015). Thus, multiple behavioral selection processes could contribute to compulsive symptoms (Sjoerds et al., 2014; Piantadosi and Ahmari, 2015). The corticolimbic-VS network is well positioned to modulate 
aspects of habitual, goal-directed, and Pavlovian behavior in $\mathrm{OCD}$, as discussed further below.

\section{The Corticolimbic-Ventral Striatal Network Subserves Performance of Goal-Directed Behavior}

The VS guides performance of goal-directed behaviors (Cardinal et al., 2002a; Yin et al., 2008; Hart et al., 2014), and the importance of this region is most apparent when greater levels of motivation or behavioral organization are required. For instance, while NAc core lesions do not disrupt performance of actions resulting in immediate delivery of outcomes, acquisition is impaired when reinforcement is delayed (Cardinal et al., 2002b; Cardinal and Cheung, 2005). Additionally, depleting dopamine levels in the NAc selectively impairs behavioral performance when large numbers of actions are required (Aberman and Salamone, 1999). These findings suggest that VS, in conjunction with VTA dopamine neurons, encodes information critical for performing behavior across delays in time and until behavioral requirements are fulfilled. Thus, the VS facilitates and sustains performance of complex goal-directed behaviors.

While some earlier work suggested that NAc does not support sensitivity to outcome value (Balleine and Killcross, 1994), lesions of the NAc core cause animals to respond equivalently for devalued and non-devalued outcomes (Corbit et al., 2001), suggesting that NAc core facilitates selective outcome value-based performance. Disconnection of basolateral amygdala and NAc core also produces deficits in selective outcome value sensitivity (Shiflett and Balleine, 2010). As noted above, medial orbitofrontal lesions impair value comparisons between different outcomes (Noonan et al., 2010). These findings suggest that the VS, in conjunction with the mOFC, dopamine system, and basolateral amygdala, could underlie outcome-value comparisons, behavioral selection, and performance of goaldirected behavioral choice (Figure 4).

\section{Theoretical Contributions of Corticolimbic-Ventral Striatal Dysregulation to Habitual and Goal-Directed Behaviors}

Habitual behaviors often emerge when regions supporting goaldirected behaviors are compromised (Balleine and Dickinson, 1998; Killcross and Coutureau, 2003; Daw et al., 2005; Yin et al., 2005, 2006; Yin and Knowlton, 2006; Gruner et al., 2015). As discussed in the preceding sections, OCD is associated with many examples of disrupted information processing (Figure 4) in networks supporting goal-directed behavior, which could potentially bias behavior toward habit-like selection via improper or ineffective evaluation and representations of actions and outcomes (Gruner et al., 2015). Consistent with this idea, OCD patients form habits more readily than healthy controls (Gillan and Robbins, 2014; Gillan et al., 2014, 2015). VS connections with dopamine neurons projecting to dorsal striatum could form a polysynaptic pathway to dorsal striatal regions commonly associated with habitual behavior. Through this pathway, dysregulation in VS could theoretically contribute to habit-like production of compulsive behaviors in OCD.

Damage to the VS also alters goal-directed decision-making (Floresco et al., 2008). For instance, NAc core lesions cause rats to make risk-averse choices (Cardinal and Howes, 2005) and prefer smaller rewards at shorter delays (Cardinal et al., 2001; Mar et al., 2011). Compromised VS information processing in patients with OCD could therefore impair or alter decisionmaking processes. In turn, this could lead to goal-directed selection of compulsive behaviors, if the patient believes their compulsions are either less risky (because of beliefs that performing the compulsion will prevent the outcome associated with the obsessive thought), or more likely to lead to immediate reward (because performing the compulsion leads to immediate anxiety relief). The basic premise of these notions is consistent with cognitive and goal-directed models of compulsive behavior in OCD (Piantadosi and Ahmari, 2015). Synthesizing these points with those mentioned in the preceding paragraph suggests that disrupted VS activity could theoretically lead to selection of compulsive behaviors via either habit-like or goal-directed mechanisms.

\section{The Corticolimbic-Ventral Striatal Network Underlies Pavlovian Influences on Behavior}

Strong evidence shows that VS is essential for Pavlovian conditioning (Cardinal et al., 2002a; Yin et al., 2008), including studies demonstrating that lesions of the NAc core impair Pavlovian autoshaping (Parkinson et al., 2000), and produce deficits in reestablishing pre-lesion Pavlovian approach (Parkinson et al., 1999). As discussed below, Pavlovian learning requires converging limbic inputs from amygdala and VTA to the VS, which emphasizes the importance of interregional signaling for the role of VS in cognition (Kelley, 2004).

The VTA is particularly important in this regard, because it is the main source of dopamine for the VS. Several lines of evidence highlight the contributions of this projection system to Pavlovian behavior. First, dopamine receptor blockade disrupts acquisition and performance of conditioned approach to stimuli associated with reward (Di Ciano et al., 2001). Similarly, lesioning dopaminergic inputs to the NAc with 6hydroxydopamine impairs acquisition of Pavlovian approach behavior (Parkinson et al., 2002), and post-training infusion of D1 dopamine receptor antagonists blocks consolidation of Pavlovian associations (Dalley et al., 2005). Taken together, this suggests that VS and the VTA dopaminergic neurons that project to the VS form part of a network mediating Pavlovian conditioning.

The amygdala also serves as an ideal candidate to support Pavlovian conditioning, because disconnecting basolateral amygdala and VS via contralateral lesions disrupts performance of conditioned place preference (Everitt et al., 1991), and impairs both autoshaping (Chang et al., 2012) and second order conditioning (Setlow et al., 2002). Thus, the basolateral amygdala's connections to the VS also strongly contribute to Pavlovian conditioning. 


\section{Theoretical model of dysregulated corticolimbic-VS information processing in OCD}

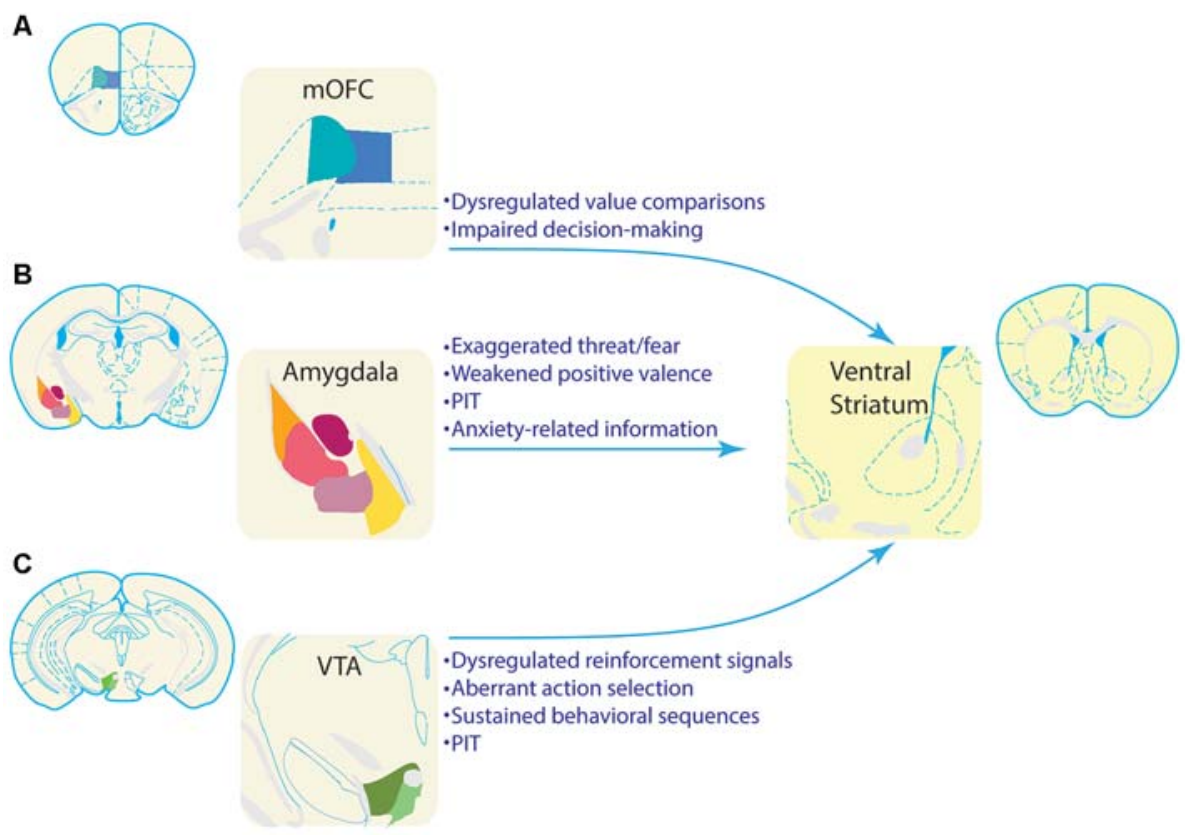

FIGURE 4 | Theoretical model of how dysregulated information processing in corticolimbic inputs to ventral striatum could underlie compulsive behavior in OCD. Each of the corticolimbic inputs highlighted in this review are depicted in the left column. VS is depicted in the right column for illustrative purposes. Bulleted text highlights information that is processed by each input region, and could theoretically be a source of dysregulated information processing in VS of OCD patients. (A) Value comparisons and decision-making are important functions of mOFC. Aberrant representations of this information could lead individuals with OCD to improperly evaluate behavioral choices. This could, in turn, lead to inflated valuation, and subsequent selection of compulsive behaviors. Alternatively, these aberrant representations could render goal-directed decision making ineffective, and bias behavioral control toward habit-like selection of compulsive behaviors. (B) The amygdala processes threatening/fearful stimuli, rewarding stimuli, and aversive stimuli. Aberrant representations of this information in OCD could lead to improper behavioral selection and compulsive behavior. As summarized in the text, amygdala is often hypoactive in response to rewarding or neutral stimuli, and hyperactive in response to threatening or symptom-provoking stimuli, which could lead to excessive influence of these stimuli over behavior. This is consistent with clinical observations of provocation of compulsive behaviors by environmental stimuli that are perceived as threatening. Amygdala projections to VS are particularly important to Pavlovian instrumental transfer (PIT). Symptom provoking stimuli could theoretically acquire an influence over behavior through PIT, and thus, dysregulation of PIT could also contribute to OCD. Amygdala is also important for processing anxiety, which is associated with the generation and/or maintenance of compulsive behaviors in OCD; this link places special emphasis on amygdala-based information processing in OCD. (C) The VTA is a major source of dopamine input to VS, and processes reinforcement signals which inform behavioral selection. This input is also necessary for sustaining behavioral sequences and effortful behavior. Considerable evidence suggests that OCD is associated with dysregulation of the dopamine system, potentially leading to a hyperdopaminergic state. These disruptions would theoretically impact information processing necessary for selecting and sustaining behavioral sequences, and could promote compulsive behavioral patterns. VTA input to VS is also necessary for PIT, and a hyperdopaminergic state could also contribute to the ability of environmental stimuli to impact behavioral selection in OCD.

Pavlovian associations can influence performance of instrumental behaviors via the process of Pavlovian to instrumental transfer (PIT), which occurs when presentation of a conditioned stimulus associated with reward increases instrumental responding (Estes, 1948). Lesion studies demonstrate that NAc core and shell support PIT (Corbit et al., 2001; Corbit and Balleine, 2011). Dopamine bidirectionally modulates PIT, as VTA inactivation attenuates PIT (Murschall and Hauber, 2006; Corbit et al., 2007), and intra-accumbens microinjections of amphetamine, an indirect dopamine agonist, enhance PIT (Wyvell and Berridge, 2000). Amygdala projections to the VTA also contribute to PIT (Corbit and Balleine, 2005; Shiflett and Balleine, 2010). Finally, OFC lesions decrease PIT, though it is unclear if this effect generalizes to both medial and lateral OFC (Ostlund and Balleine, 2007a,b; Balleine et al., 2011). Thus, the combined network of VS, amygdala, VTA, and
OFC produce a motivational effect of Pavlovian associations on performance of instrumental behaviors.

\section{Dysregulation of Corticolimbic-Ventral Striatal Networks could Promote Pavlovian Influences on Compulsive OCD Symptomatology}

It is critical to note the impact of Pavlovian motivational influences on behavioral selection, because abnormally high motivation to select a behavior may be a critical feature of compulsivity (Sjoerds et al., 2014; Piantadosi and Ahmari, 2015). For instance, symptom-provoking stimuli may have excessively strong conditioned associations with aversive outcomes (Simon et al., 2010; Ludvik et al., 2015). These stimuli could, in turn, bias behavioral selection and motivate compulsive behavior through 
PIT of aversive associations, or Pavlovian fear conditioninglike processes (Figure 4). The abnormally strong amygdala activation or hyperdopaminergia that may occur in OCD patients (Breiter et al., 1996; Denys et al., 2004a; Mataix-Cols et al., 2004; van den Heuvel et al., 2004; Simon et al., 2010, 2014; Milad and Rauch, 2012; Klanker et al., 2013) could underlie this motivational influence on behavioral selection. This notion is in line with previous suggestions that the corticolimbic regions addressed in this review process affect and value, and inform behavioral selection in VS (Mogenson et al., 1980; Cardinal et al., 2002a; Wise, 2004; Sesack and Grace, 2010; Zorrilla and Koob, 2013). Further support for aberrant Pavlovian information processing in OCD patients is provided by recent findings of abnormal Pavlovian fear extinction in patients with OCD (Milad et al., 2013; McLaughlin et al., 2015). Consistent with the idea that Pavlovian processes could underlie symptomology, extinguishing negative conditioned associations via exposure to symptom provoking stimuli has proven efficacious in OCD patients (Foa et al., 2005; Franklin and Foa, 2011; Simpson et al., 2013; Lewin et al., 2014; Ludvik et al., 2015).

\section{PREDICTIONS OF CORTICOLIMBIC-VENTRAL STRIATAL MODEL}

We have discussed the evidence suggesting that affective dysregulation is a key component of OCD, as well as evidence indicative of amygdala, OFC, and VTA pathologies in OCD. We also highlighted theoretical interregional circuit level mechanisms that could mediate or contribute to compulsive behavioral selection. These points lead to at least three additional predictions: (1) functional and structural abnormalities in VS should be present in patients with OCD; (2) a causal relationship should exist between corticolimbic-VS hyperactivity and compulsive-like behaviors in animal models; and (3) interventions which target the VS should ameliorate both affective and compulsive symptoms. The remainder of this review will explore these points below.

\section{Prediction 1: Structural and Functional Abnormalities in Ventral Striatum are Observed in Patients with OCD}

In support of this prediction, non-medicated OCD patients have increased local connectivity in the VS compared to medicated patients and healthy controls (Beucke et al., 2013). As assessed by diffusion-weighted imaging, patients with OCD also have increased connectivity between the VS and OFC (Nakamae et al., 2014). This finding is key, because it confirms the presence of aberrant anatomical connectivity between VS and other networks implicated in OCD. Significant negative correlations between NAc volume and YBOCS scores have also been found (Narayanaswamy et al., 2013), and further suggest that these structural abnormalities play a key role in the disorder. In addition to aberrant anatomical connectivity, there is increased resting state functional connectivity between VS and OFC (Harrison et al., 2009; Sakai et al., 2011). It should be noted, however, that one study has shown that VS functional connectivity is not correlated with symptom severity (Sakai et al., 2011), and that some groups have reported decreased connectivity between VS and frontal cortex regions (Admon et al., 2012; Posner et al., 2014).

In addition to changes in connectivity, VS is also associated with aberrant task-evoked activity and altered communication with other brain regions in OCD. Functional imaging studies demonstrate that during anticipation of a monetary reward, healthy controls have increased VS activity. In patients with OCD, however, this activity is significantly reduced (Figee et al., 2011). Decreased VS activity at reward receipt has also been found in patients with OCD (Admon et al., 2012). These findings are critical because they demonstrate dysregulated information processing in the VS of patients, which confirms localization of pathophysiological activity to VS in OCD. These findings also demonstrate abnormal activity related to understanding the consequences of one's actions, transferring motivational information to action selection, and/or reward processing. Thus, these data support a part of our central thesis: that dysregulation in corticolimbic-VS networks of patients with OCD leads to deficits in processing information critical for selecting behaviors.

\section{Prediction 2: Aberrant Activity in Ventral Striatal Circuits Causes Compulsive-Like Behaviors}

While it has been hypothesized that dysregulated communication in corticolimbic inputs to VS could give rise to compulsive behavior, this is difficult to conclusively prove in humans. Animal studies can be used to address this hypothesis by allowing researchers to investigate causal relationships between abnormal VS inputs and OCD-like phenotypes (Monteiro and Feng, 2015). To perform a direct test of this idea, our group recently modeled mOFC-VS hyperactivity using optogenetics in mice. Brief, repeated, optogenetic stimulation of mOFC terminals in VS progressively led to the development of repetitive grooming behavior that may be relevant to OCD (Ahmari et al., 2013). This repeated stimulation likely led to pathological plasticity, as acute stimulation did not produce this behavioral effect, and the behavioral phenotype emerged in conjunction with an increase in VS firing rates evoked by OFC stimulation. This finding is especially interesting in light of the aforementioned increased functional connectivity of mOFC and VS in patients with OCD, which may be mimicked by the stimulation-induced plasticity. Importantly, both the behavioral and electrophysiological effects of stimulation were reversed by chronic administration of high-dose fluoxetine, a first line treatment for OCD. Together, these data suggest that abnormal functional connectivity in this interregional connection could underlie pathological repetitive behaviors (Ahmari et al., 2013).

Demonstrating causality, not just correlation, between hyperactivity in VS circuitry and OCD-like behaviors in a 
rodent model strongly suggests that corticolimbic-VS networks could directly contribute to compulsive behaviors in OCD. The spatial specificity of this manipulation is critically important; this optogenetic paradigm selectively stimulated mOFC connections in the VS, so that the behavioral effects of the manipulation originated in a circuit implicated in the pathophysiology of OCD. While these findings demonstrate that a circuitlevel manipulation of OFC-VS projections produces OCD-like behaviors in mice (Ahmari et al., 2013), all the corticolimbic inputs detailed in this review could theoretically contribute to compulsive behavioral selection; however, this has not been demonstrated at the present time. While future work should investigate the relationship between dysregulation throughout this network and compulsive-like behaviors, the available data confirm another part of the central thesis of this review: dysregulation of interregional activity in VS circuits is sufficient to cause compulsive-like behavior.

\section{Prediction 3: Treatments Targeting Ventral Striatal Circuits Ameliorate Affective, Obsessive, and Compulsive Symptoms in Patients with OCD}

A final point suggesting that VS circuits contribute to OCD symptomatology is that deep brain stimulation (DBS) in the VS has been shown to improve affective, obsessive, and compulsive symptomatology. Though it should be noted that targeting internal capsule, thalamic peduncle, and subthalamic nucleus has also yielded positive clinical effects (de Koning et al., 2011), we focus here on data from DBS treatment in the VS to convey that this is a locus of effective intervention in OCD.

In an early pilot study, unilateral DBS in the NAc shell improved symptoms in three of four patients tested (Sturm et al., 2003). A subsequent open trial in 10 adult patients demonstrated that bilateral DBS in VS/ventral capsule decreased obsessivecompulsive symptoms from severe to moderate, and improved depression and anxiety ratings three years after treatment was initiated (Greenberg et al., 2006). These studies were highly suggestive that VS DBS could be beneficial for treating OCD. Due to the inevitable difficulties in studying experimental surgical procedures, however, these first studies suffered from low numbers of patients and a lack of double blinding. More recent work has addressed these issues. A combined multi-site, longterm study indicates that VS DBS reduced OCD symptoms in over $60 \%$ of the 26 patients who had previously been treatment resistant (Greenberg et al., 2010). Affective symptoms, such as anxiety and depression, were improved in these patients as well (Greenberg et al., 2010). Additionally, Denys et al. (2010) conducted a study with eight months of open treatment, followed by a double-blind crossover phase and resumption of open treatment. Both the open phase and the double-blind crossover phase were associated with decreases in YBOCS scores, anxiety, and depression symptoms. Thus, DBS in the VS of OCD patients has been shown to be an effective treatment for both obsessivecompulsive and affective symptoms.

In addition to improving symptoms, NAc DBS has been shown to reduce functional connectivity with lateral and medial prefrontal cortex (Figee et al., 2013). Thus, DBS can ameliorate not only symptomatology, but also underlying circuit abnormalities. NAc DBS has also been found to decrease D2/3 dopamine receptor binding and dopamine metabolite levels (Figee et al., 2014), and may therefore correct the dopaminergic abnormalities that have been reported in patients with OCD (see above). Additionally, abnormal low frequency $(2-5 \mathrm{~Hz})$ oscillations in the frontal cortex are observed in OCD, and NAC DBS reduces the power of these oscillations (Figee et al., 2013). Taken together, these data demonstrate that NAc or VS DBS can reverse neuronal activity disruptions linked to OCD. The reductions in affective, obsessive, and compulsive symptoms, coupled with alterations in neuronal activity, all support the notion that the VS is a locus of effective intervention in OCD.

Insight into the mechanisms underlying this clinical effect can be provided by animal studies. DBS in rat VS subregions receiving preferential innervation from mOFC (dorsal to the anterior commissure) causes increased expression of plasticity markers and neurotrophic growth factors in the mOFC and amygdala (Do-Monte et al., 2013; Rodriguez-Romaguera et al., 2015). It has also been suggested that DBS may override hyperactivity in cortico-striatal projections (Tass et al., 2003); in accord with this hypothesis, NAc DBS decreases orbitofrontal cortex neuronal activity in anesthetized rats (McCracken and Grace, 2007). Taken together, these data suggest that in rodents, DBS in some portions of VS produces electrophysiological changes and plasticity in multiple corticolimbic regions that are linked to compulsivity.

\section{CLOSING STATEMENTS-THE EMERGING ROLE OF CORTICOLIMBIC-VENTRAL STRIATAL NETWORKS IN OCD}

In closing, we have examined how abnormal activity in amygdala, VTA, and mOFC could lead to aberrant or dysregulated affective representations. These representations may, in turn, impact information processing in the VS, and promote compulsive behavioral selection in patients with OCD. Though areas outside of this network are also clearly important in OCD pathophysiology, our focus on this corticolimbic-VS network complements more extensively studied dorsal striatal circuits by emphasizing the role of affective dysregulation in producing compulsive behavior. In support of this VS model, anatomical or functional abnormalities have been observed in all regions of this network in patients with OCD. Additionally, circuit level disruptions in the VS produce compulsive-like behavior in animal models, and VS DBS can ameliorate both affective and obsessive-compulsive symptomatology in patients with OCD. Much of the data supporting these final two points has emerged within the last decade. Thus, this is a critical period in the study of this severe neuropsychiatric disorder, as new data and treatment approaches contribute to an emerging understanding of the role of corticolimbic-ventral striatal networks in OCD. Collectively, the data highlighted here suggest that the affective dysregulation that is associated with OCD, and aberrant information processing by medial orbitofrontal, VTA, and 
amygdala inputs to the VS, are critical to producing OCD symptoms. Thus, this network plays a potentially critical role, and is fertile ground for future theoretical and experimental investigations on the origins and treatment of OCD.

\section{FUNDING}

Funding was provided by the National Institute of Mental Health K08 MH087718, R21 MH096200, R01 MH104255; and by the

\section{REFERENCES}

Aberman, J. E., and Salamone, J. D. (1999). Nucleus accumbens dopamine depletions make rats more sensitive to high ratio requirements but do not impair primary food reinforcement. Neuroscience 92, 545-552. doi: 10. 1016/s0306-4522(99)00004-4

Admon, R., Bleich-Cohen, M., Weizmant, R., Poyurovsky, M., Faragian, S., and Hendler, T. (2012). Functional and structural neural indices of risk aversion in obsessive-compulsive disorder (OCD). Psychiatry Res. 203, 207-213. doi: 10. 1016/j.pscychresns.2012.02.002

Ahmari, S. E. (2015). Using mice to model obsessive compulsive disorder: from genes to circuits. Neurosci. doi: 10.1016/j.neuroscience.2015.11.009 [Epub ahead of print].

Ahmari, S. E., and Dougherty, D. D. (2015). Dissecting ocd circuits: from animal models to targeted treatments. Depress. Anxiety 32, 550-562. doi: 10.1002/da. 22367

Ahmari, S. E., Spellman, T., Douglass, N. L., Kheirbek, M. A., Simpson, H. B., Deisseroth, K., et al. (2013). Repeated cortico-striatal stimulation generates persistent OCD-like behavior. Science 340, 1234-1239. doi: 10.1126/science, 1234733

Albelda, N., and Joel, D. (2012). Animal models of obsessive-compulsive disorder: exploring pharmacology and neural substrates. Neurosci. Biobehav. Rev. 36, 47-63. doi: 10.1016/j.neubiorev.2011.04.006

Albin, R. L., Young, A. B., and Penney, J. B. (1989). The functional anatomy of basal ganglia disorders. Trends Neurosci. 12, 366-375. doi: 10.1016/01662236(89)90074-x

Alptekin, K., Degirmenci, B., Kivircik, B., Durak, H., Yemez, B., Derebek, E., et al. (2001). Tc-99m HMPAO brain perfusion SPECT in drug-free obsessivecompulsive patients without depression. Psychiatry Res. 107, 51-56. doi: 10. 1016/s0925-4927(01)00086-5

Alsobrook, J. P. 2nd, Zohar, A. H., Leboyer, M., Chabane, N., Ebstein, R. P., and Pauls, D. L. (2002). Association between the COMT locus and obsessivecompulsive disorder in females but not males. Am. J. Med. Genet. 114, 116-120. doi: 10.1002/ajmg.10040

American Psychiatric Association D-TF. (2013). Diagnostic and Statistical Manual of Mental Disorders: DSM-5. 5th Edn. Washington, DC: American Psychiatric Association.

Atmaca, M., Yildirim, B. H., Ozdemir, B. H., Aydin, B. A., Tezcan, A. E., and Ozler, A. S. (2006). Volumetric MRI assessment of brain regions in patients with refractory obsessive-compulsive disorder. Prog. Neuropsychopharmacol. Biol. Psychiatry 30, 1051-1057. doi: 10.1016/j.pnpbp.2006.03.033

Balleine, B. W., and Dickinson, A. (1998). Goal-directed instrumental action: contingency and incentive learning and their cortical substrates. Neuropharmacology $\quad 37, \quad 407-419$. doi: 10.1016/s0028-3908(98) 00033-1

Balleine, B., and Killcross, S. (1994). Effects of ibotenic acid lesions of the nucleus accumbens on instrumental action. Behav. Brain Res. 65, 181-193. doi: 10. 1016/0166-4328(94)90104-x

Balleine, B. W., Leung, B. K., and Ostlund, S. B. (2011). The orbitofrontal cortex, predicted value and choice. Ann. N Y Acad. Sci. 1239, 43-50. doi: 10.1111/j. 1749-6632.2011.06270.x

Balleine, B. W., and O'Doherty, J. P. (2010). Human and rodent homologies in action control: corticostriatal determinants of goal-directed and habitual action. Neuropsychopharmacology 35, 48-69. doi: 10.1038/npp. 2009.131
Brain and Behavior Research Foundation Young Investigator Award, Burroughs Wellcome Fund CAMS Award, MQ Fellows Award, and the McKnight Foundation Scholars Award.

\section{ACKNOWLEDGMENTS}

The authors wish to thank Dr. Nicholas W. Simon, Sweyta Lohani, and Dr. Mary Torregrossa for helpful comments on an earlier version of this review.

Bartz, J. A., and Hollander, E. (2006). Is obsessive-compulsive disorder an anxiety disorder? Prog. Neuropsychopharmacol. Biol. Psychiatry 30, 338-352. doi: 10. 1016/j.pnpbp.2005.11.003

Bassett, D. S., and Bullmore, E. T. (2009). Human brain networks in health and disease. Curr. Opin. Neurol. 22, 340-347. doi: 10.1097/WCO. 0b013e32832d93dd

Baxter, L. R. Jr., Schwartz, J. M., Mazziotta, J. C., Phelps, M. E., Pahl, J. J., Guze, B. H., et al. (1988). Cerebral glucose metabolic rates in nondepressed patients with obsessive-compulsive disorder. Am. J. Psychiatry 145, 1560-1563. doi: 10. 1176/ajp.145.12.1560

Berendse, H. W., Groenewegen, H. J., and Lohman, A. H. (1992). Compartmental distribution of ventral striatal neurons projecting to the mesencephalon in the rat. J. Neurosci. 12, 2079-2103.

Berridge, K. C., Aldridge, J. W., Houchard, K. R., and Zhuang, X. (2005). Sequential super-stereotypy of an instinctive fixed action pattern in hyperdopaminergic mutant mice: a model of obsessive compulsive disorder and Tourette's. BMC Biol. 3:4. doi: 10.1186/1741-7007-3-4

Beucke, J. C., Sepulcre, J., Talukdar, T., Linnman, C., Zschenderlein, K., Endrass, T., et al. (2013). Abnormally high degree connectivity of the orbitofrontal cortex in obsessive-compulsive disorder. JAMA Psychiatry 70, 619-629. doi: 10. 1001/jamapsychiatry.2013.173

Bienvenu, O. J., Samuels, J. F., Wuyek, L. A., Liang, K. Y., Wang, Y., Grados, M. A., et al. (2012). Is obsessive-compulsive disorder an anxiety disorder and what, if any, are spectrum conditions? A family study perspective. Psychol. Med. 42, 1-13. doi: 10.1017/S0033291711000742

Black, D. W., Noyes, R. Jr., Goldstein, R. B., and Blum, N. (1992). A family study of obsessive-compulsive disorder. Arch. Gen. Psychiatry 49, 362-368. doi: 10. 1001/archpsyc.1992.01820050026004

Bravo-Rivera, C., Roman-Ortiz, C., Brignoni-Perez, E., Sotres-Bayon, F., and Quirk, G. J. (2014). Neural structures mediating expression and extinction of platform-mediated avoidance. J. Neurosci. 34, 9736-9742. doi: 10. 1523/JNEUROSCI.0191-14.2014

Breiter, H. C., Rauch, S. L., Kwong, K. K., Baker, J. R., Weisskoff, R. M., Kennedy, D. N., et al. (1996). Functional magnetic resonance imaging of symptom provocation in obsessive-compulsive disorder. Arch. Gen. Psychiatry 53, 595-606. doi: 10.1001/archpsyc.1996.01830070041008

Britton, J. C., Stewart, S. E., Killgore, W. D., Rosso, I. M., Price, L. M., Gold, A. L., et al. (2010). Amygdala activation in response to facial expressions in pediatric obsessive-compulsive disorder. Depress. Anxiety 27, 643-651. doi: 10.1002/da. 20718

Brown, H. D., McCutcheon, J. E., Cone, J. J., Ragozzino, M. E., and Roitman, M. F. (2011). Primary food reward and reward-predictive stimuli evoke different patterns of phasic dopamine signaling throughout the striatum. Eur. J. Neurosci. 34, 1997-2006. doi: 10.1111/j.1460-9568.2011. 07914.x

Burguière, E., Monteiro, P., Feng, G., and Graybiel, A. M. (2013). Optogenetic stimulation of lateral orbitofronto-striatal pathway suppresses compulsive behaviors. Science 340, 1243-1246. doi: 10.1126/science. 1232380

Burguière, E., Monteiro, P., Mallet, L., Feng, G., and Graybiel, A. M. (2015). Striatal circuits, habits and implications for obsessive-compulsive disorder. Curr. Opin. Neurobiol. 30, 59-65. doi: 10.1016/j.conb.2014.08.008

Bystritsky, A., Liberman, R. P., Hwang, S., Wallace, C. J., Vapnik, T., Maindment, K., et al. (2001). Social functioning and quality of life comparisons between obsessive-compulsive and schizophrenic disorders. Depress. Anxiety 14, 214-218. doi: 10.1002/da.1069 
Cador, M., Robbins, T., and Everitt, B. (1989). Involvement of the amygdala in stimulus-reward associations: interaction with the ventral striatum. Neuroscience 30, 77-86. doi: 10.1016/0306-4522(89) 90354-0

Cannistraro, P. A., Wright, C. I., Wedig, M. M., Martis, B., Shin, L. M., Wilhelm, S., et al. (2004). Amygdala responses to human faces in obsessive-compulsive disorder. Biol. Psychiatry 56, 916-920. doi: 10.1016/j.biopsych.2004.09.029

Cardinal, R. N., and Cheung, T. H. (2005). Nucleus accumbens core lesions retard instrumental learning and performance with delayed reinforcement in the rat. BMC Neurosci. 6:9. doi: 10.1186/1471-2202-6-9

Cardinal, R. N., and Howes, N. J. (2005). Effects of lesions of the nucleus accumbens core on choice between small certain rewards and large uncertain rewards in rats. BMC Neurosci. 6:37. doi: 10.1186/1471-2202-6-37

Cardinal, R., Parkinson, J., Hall, J., and Everitt, B. (2002a). Emotion and motivation: the role of the amygdala, ventral striatum and prefrontal cortex. Neurosci. Biobehav. Rev. 26, 321-352. doi: 10.1016/s0149-7634(02)00007-6

Cardinal, R., Parkinson, J., Lachenal, G., Halkerston, K., Rudarakanchana, N., Hall, J., et al. (2002b). Effects of selective excitotoxic lesions of the nucleus accumbens core, anterior cingulate cortex and central nucleus of the amygdala on autoshaping performance in rats. Behav. Neurosci. 116, 553-567. doi: 10. 1037/0735-7044.116.4.553

Cardinal, R. N., Pennicott, D. R., Sugathapala, C. L., Robbins, T. W., and Everitt, B. J. (2001). Impulsive choice induced in rats by lesions of the nucleus accumbens core. Science 292, 2499-2501. doi: 10.1126/science.1060818

Carlezon, W. A. Jr., and Thomas, M. J. (2009). Biological substrates of reward and aversion: a nucleus accumbens activity hypothesis. Neuropharmacology 56(Suppl. 1), 122-132. doi: 10.1016/j.neuropharm.2008.06.075

Carr, D. B., and Sesack, S. R. (2000). GABA-containing neurons in the rat ventral tegmental area project to the prefrontal cortex. Synapse 38, 114-123. doi: 10. 1002/1098-2396(200011)38:2<114::aid-syn2>3.0.co;2-r

Chamberlain, S. R., Menzies, L., Hampshire, A., Suckling, J., Fineberg, N. A., del Campo, N., et al. (2008). Orbitofrontal dysfunction in patients with obsessivecompulsive disorder and their unaffected relatives. Science 321, 421-422. doi: 10.1126/science. 1154433

Chang, S. E., Wheeler, D. S., and Holland, P. C. (2012). Roles of nucleus accumbens and basolateral amygdala in autoshaped lever pressing. Neurobiol. Learn. Mem. 97, 441-451. doi: 10.1016/j.nlm.2012.03.008

Charara, A., and Grace, A. A. (2003). Dopamine receptor subtypes selectively modulate excitatory afferents from the hippocampus and amygdala to rat nucleus accumbens neurons. Neuropsychopharmacology 28, 1412-1421. doi: 10 . 1038/sj.npp. 1300220

Cheer, J. F., Heien, M. L., Garris, P. A., Carelli, R. M., and Wightman, R. M. (2005). Simultaneous dopamine and single-unit recordings reveal accumbens GABAergic responses: implications for intracranial self-stimulation. Proc. Natl. Acad. Sci. U S A 102, 19150-19155. doi: 10.1073/pnas.0509607102

Colle, L. M., and Wise, R. A. (1991). Circling induced by intra-accumbens amphetamine injections. Psychopharmacology (Berl) 105, 157-161. doi: 10. 1007/bf02244302

Corbit, L. H., and Balleine, B. W. (2005). Double dissociation of basolateral and central amygdala lesions on the general and outcome-specific forms of pavlovian-instrumental transfer. J. Neurosci. 25, 962-970. doi: 10. 1523/jneurosci.4507-04.2005

Corbit, L. H., and Balleine, B. W. (2011). The general and outcome-specific forms of Pavlovian-instrumental transfer are differentially mediated by the nucleus accumbens core and shell. J. Neurosci. 31, 11786-11794. doi: 10. 1523/JNEUROSCI.2711-11.2011

Corbit, L. H., Janak, P. H., and Balleine, B. W. (2007). General and outcomespecific forms of Pavlovian-instrumental transfer: the effect of shifts in motivational state and inactivation of the ventral tegmental area. Eur. J. Neurosci. 26, 3141-3149. doi: 10.1111/j.1460-9568.2007.05934.x

Corbit, L., Muir, J., and Balleine, B. (2001). The role of the nucleus accumbens in instrumental conditioning: evidence of a functional dissociation between accumbens core and shell. J. Neurosci. 21, 3251-3260.

Craig, K. J., and Fineberg, N. A. (2008). OCD and anxiety: from afterthought to independence. J. Psychopharmacol 22, 217-219. doi: 10. $1177 / 0269881107081506$

Crick, F., and Koch, C. (2003). A framework for consciousness. Nat. Neurosci. 6, 119-126. doi: 10.1038/nn0203-119
Crittenden, J. R., and Graybiel, A. M. (2011). Basal Ganglia disorders associated with imbalances in the striatal striosome and matrix compartments. Front. Neuroanat. 5:59. doi: 10.3389/fnana.2011.00059

Dalley, J. W., Lääne, K., Theobald, D. E., Armstrong, H. C., Corlett, P. R., Chudasama, Y., et al. (2005). Time-limited modulation of appetitive Pavlovian memory by D1 and NMDA receptors in the nucleus accumbens. Proc. Natl. Acad. Sci. U S A 102, 6189-6194. doi: 10.1073/pnas.0502080102

Davis, M. (1992). The role of the amygdala in fear and anxiety. Annu. Rev. Neurosci. 15, 353-375. doi: 10.1146/annurev.neuro.15.1.353

Daw, N. D., Niv, Y., and Dayan, P. (2005). Uncertainty-based competition between prefrontal and dorsolateral striatal systems for behavioral control. Nat. Neurosci. 8, 1704-1711. doi: 10.1038/nn1560

de Haan, S., Rietveld, E., Stokhof, M., and Denys, D. (2013). The phenomenology of deep brain stimulation-induced changes in OCD: an enactive affordancebased model. Front. Hum. Neurosci. 7:653. doi: 10.3389/fnhum.2013.00653

de Koning, P. P., Figee, M., van den Munckhof, P., Schuurman, P. R., and Denys, D. (2011). Current status of deep brain stimulation for obsessive-compulsive disorder: a clinical review of different targets. Curr. Psychiatry Rep. 13, 274-282. doi: 10.1007/s11920-011-0200-8

Denys, D., Mantione, M., Figee, M., van den Munckhof, P., Koerselman, F., Westenberg, H., et al. (2010). Deep brain stimulation of the nucleus accumbens for treatment-refractory obsessive-compulsive disorder. Arch. Gen. Psychiatry 67, 1061-1068. doi: 10.1001/archgenpsychiatry.2010.122

Denys, D., Zohar, J., and Westenberg, H. G. (2004a). The role of dopamine in obsessive-compulsive disorder: preclinical and clinical evidence. J. Clin. Psychiatry 65(Suppl. 14), 11-17.

Denys, D., van der Wee, N., Janssen, J., De Geus, F., and Westenberg, H. G. (2004b). Low level of dopaminergic D2 receptor binding in obsessivecompulsive disorder. Biol. Psychiatry 55, 1041-1045. doi: 10.1016/j.biopsych. 2004.01.023

Denys, D., Tenney, N., van Megen, H. J., de Geus, F., and Westenberg, H. G. (2004c). Axis I and II comorbidity in a large sample of patients with obsessivecompulsive disorder. J. Affect. Disord. 80, 155-162. doi: 10.1016/s01650327(03)00056-9

de Wit, S., and Dickinson, A. (2009). Associative theories of goal-directed behaviour: a case for animal-human translational models. Psychol. Res. 73, 463-476. doi: 10.1007/s00426-009-0230-6

Di Ciano, P., Cardinal, R. N., Cowell, R. A., Little, S. J., and Everitt, B. J. (2001). Differential involvement of NMDA, AMPA/kainate and dopamine receptors in the nucleus accumbens core in the acquisition and performance of pavlovian approach behavior. J. Neurosci. 21, 9471-9477.

Do-Monte, F. H., Rodriguez-Romaguera, J., Rosas-Vidal, L. E., and Quirk, G. J. (2013). Deep brain stimulation of the ventral striatum increases BDNF in the fear extinction circuit. Front. Behav. Neurosci. 7:102. doi: 10.3389/fnbeh.2013. 00102

Einat, H., and Szechtman, H. (1995). Perseveration without hyperlocomotion in a spontaneous alternation task in rats sensitized to the dopamine agonist quinpirole. Physiol. Behav. 57, 55-59. doi: 10.1016/0031-9384(94)00209-n

Estes, W. K. (1948). Discriminative conditioning. II. Effects of a Pavlovian conditioned stimulus upon a subsequently established operant response. J. Exp. Psychol. 38, 173-177. doi: /10.1037/h0057525

Everitt, B. J., Cador, M., and Robbins, T. W. (1989). Interactions between the amygdala and ventral striatum in stimulus-reward associations: studies using a second-order schedule of sexual reinforcement. Neuroscience 30, 63-75. doi: 10. 1016/0306-4522(89)90353-9

Everitt, B., Morris, K., O'Brien, A., Burns, L., and Robbins, T. (1991). The basolateral amygdala-ventral striatal system and conditioned place preference: further evidence of limbic-striatal interactions underlying reward-related processes. Neuroscience 42, 1-18. doi: 10.1016/0306-4522(91)90145-e

Felix-Ortiz, A. C., Beyeler, A., Seo, C., Leppla, C. A., Wildes, C. P., and Tye, K. M. (2013). BLA to vHPC inputs modulate anxiety-related behaviors. Neuron 79, 658-664. doi: 10.1016/j.neuron.2013.06.016

Figee, M., de Koning, P., Klaassen, S., Vulink, N., Mantione, M., van den Munckhof, P., et al. (2014). Deep brain stimulation induces striatal dopamine release in obsessive-compulsive disorder. Biol. Psychiatry 75, 647-652. doi: 10. 1016/j.biopsych.2013.06.021

Figee, M., Luigjes, J., Smolders, R., Valencia-Alfonso, C. E., van Wingen, G., de Kwaasteniet, B., et al. (2013). Deep brain stimulation restores frontostriatal 
network activity in obsessive-compulsive disorder. Nat. Neurosci. 16, 386-387. doi: 10.1038/nn.3344

Figee, M., Vink, M., de Geus, F., Vulink, N., Veltman, D. J., Westenberg, H., et al. (2011). Dysfunctional reward circuitry in obsessive-compulsive disorder. Biol. Psychiatry 69, 867-874. doi: 10.1016/j.biopsych.2010.12.003

Finch, D. M. (1996). Neurophysiology of converging synaptic inputs from the rat prefrontal cortex, amygdala, midline thalamus and hippocampal formation onto single neurons of the caudate/putamen and nucleus accumbens. Hippocampus 6, 495-512.

Fineberg, N. A., Potenza, M. N., Chamberlain, S. R., Berlin, H. A., Menzies, L., Bechara, A., et al. (2010). Probing compulsive and impulsive behaviors, from animal models to endophenotypes: a narrative review. Neuropsychopharmacology 35, 591-604. doi: 10.1038/npp.2009.185

Floresco, S. B., St Onge, J. R., Ghods-Sharifi, S., and Winstanley, C. A. (2008). Cortico-limbic-striatal circuits subserving different forms of costbenefit decision making. Cogn. Affect. Behav. Neurosci. 8, 375-389. doi: 10. 3758/CABN.8.4.375

Foa, E. B., Liebowitz, M. R., Kozak, M. J., Davies, S., Campeas, R., Franklin, M. E., et al. (2005). Randomized, placebo-controlled trial of exposure and ritual prevention, clomipramine and their combination in the treatment of obsessivecompulsive disorder. Am. J. Psychiatry 162, 151-161. doi: 10.1176/appi.ajp.162. 1.151

Franklin, M. E., and Foa, E. B. (2011). Treatment of obsessive compulsive disorder. Annu. Rev. Clin. Psychol. 7, 229-243. doi: 10.1146/annurev-clinpsy-032210104533

Freeze, B. S., Kravitz, A. V., Hammack, N., Berke, J. D., and Kreitzer, A. C. (2013). Control of basal ganglia output by direct and indirect pathway projection neurons. J. Neurosci. 33, 18531-18539. doi: 10.1523/JNEUROSCI.1278-13.2013

French, S. J., and Totterdell, S. (2002). Hippocampal and prefrontal cortical inputs monosynaptically converge with individual projection neurons of the nucleus accumbens. J. Comp. Neurol. 446, 151-165. doi: 10.1002/cne.10191

French, S. J., and Totterdell, S. (2003). Individual nucleus accumbens-projection neurons receive both basolateral amygdala and ventral subicular afferents in rats. Neuroscience 119, 19-31. doi: 10.1016/s0306-4522(03)00150-7

Gerfen, C. R., and Surmeier, D. J. (2011). Modulation of striatal projection systems by dopamine. Annu. Rev. Neurosci. 34, 441-466. doi: 10.1146/annurev-neuro061010-113641

Gillan, C. M., Apergis-Schoute, A. M., Morein-Zamir, S., Urcelay, G. P., Sule, A., Fineberg, N. A., et al. (2015). Functional neuroimaging of avoidance habits in obsessive-compulsive disorder. Am. J. Psychiatry 172, 284-293. doi: 10. 1176/appi.ajp.2014.14040525

Gillan, C. M., Morein-Zamir, S., Urcelay, G. P., Sule, A., Voon, V., ApergisSchoute, A. M., et al. (2014). Enhanced avoidance habits in obsessivecompulsive disorder. Biol. Psychiatry 75, 631-638. doi: 10.1016/j.biopsych. 2013.02.002

Gillan, C. M., and Robbins, T. W. (2014). Goal-directed learning and obsessivecompulsive disorder. Philos. Trans. R. Soc. Lond. B Biol. Sci. 369:20130475. doi: $10.1098 /$ rstb.2013.0475

Gittis, A. H., and Kreitzer, A. C. (2012). Striatal microcircuitry and movement disorders. Trends Neurosci. 35, 557-564. doi: 10.1016/j.tins.2012.06.008

Glimcher, P. W. (2011). Understanding dopamine and reinforcement learning: the dopamine reward prediction error hypothesis. Proc. Natl. Acad. Sci. U S A 108(Suppl. 3), 15647-15654. doi: 10.1073/pnas.1014269108

Gourley, S. L., Lee, A. S., Howell, J. L., Pittenger, C., and Taylor, J. R. (2010). Dissociable regulation of instrumental action within mouse prefrontal cortex. Eur. J. Neurosci. 32, 1726-1734. doi: 10.1111/j.1460-9568.2010.07438.x

Graybiel, A. M. (2000). The basal ganglia. Curr. Biol. 10, R509-R511. doi: 10. 1016/S0960-9822(00)00593-5

Graybiel, A. M., Ragsdale, C. W. Jr. (1978). Histochemically distinct compartments in the striatum of human, monkeys and cat demonstrated by acetylthiocholinesterase staining. Proc. Natl. Acad. Sci. U S A 75, 5723-5726. doi: $10.1073 /$ pnas.75.11.5723

Graybiel, A. M., and Rauch, S. L. (2000). Toward a neurobiology of obsessivecompulsive disorder. Neuron 28, 343-347. doi: 10.1016/s0896-6273(00) 00113-6

Greenberg, B. D., Gabriels, L. A., Malone, D. A. Jr., Rezai, A. R., Friehs, G. M., Okun, M. S., et al. (2010). Deep brain stimulation of the ventral internal capsule/ventral striatum for obsessive-compulsive disorder: worldwide experience. Mol. Psychiatry 15, 64-79. doi: 10.1038/mp.2008.55
Greenberg, B. D., Malone, D. A., Friehs, G. M., Rezai, A. R., Kubu, C. S., Malloy, P. F., et al. (2006). Three-year outcomes in deep brain stimulation for highly resistant obsessive-compulsive disorder. Neuropsychopharmacology 31, 2384-2393. doi: 10.1038/sj.npp. 1301201

Gremel, C. M., and Costa, R. M. (2013). Orbitofrontal and striatal circuits dynamically encode the shift between goal-directed and habitual actions. Nat. Commun. 4:2264. doi: 10.1038/ncomms3264

Groenewegen, H. J., Wright, C. I., and Uylings, H. B. M. (1997). The anatomical relationships of the prefrontal cortex with limbic structures and the basal ganglia. J. Psychopharmacol. 11, 99-106. doi: 10.1177/026988119701 100202

Gruner, P., Anticevic, A., Lee, D., and Pittenger, C. (2015). Arbitration between action strategies in obsessive-compulsive disorder. Neuroscientist. doi: 10. 1177/1073858414568317 [Epub ahead of print].

Haber, S. N., Fudge, J. L., and McFarland, N. R. (2000). Striatonigrostriatal pathways in primates form an ascending spiral from the shell to the dorsolateral striatum. J. Neurosci. 20, 2369-2382.

Harrison, B. J., Soriano-Mas, C., Pujol, J., Ortiz, H., López-Solà, M., HernandezRibas, R., et al. (2009). Altered corticostriatal functional connectivity in obsessive-compulsive disorder. Arch. Gen. Psychiatry 66, 1189-1200. doi: 10. 1001/archgenpsychiatry.2009.152

Hart, G., Leung, B. K., and Balleine, B. W. (2014). Dorsal and ventral streams: the distinct role of striatal subregions in the acquisition and performance of goal-directed actions. Neurobiol. Learn. Mem. 108, 104-118. doi: 10.1016/j.nlm. 2013.11.003

Hatfield, T., Han, J. S., Conley, M., Gallagher, M., and Holland, P. (1996). Neurotoxic lesions of basolateral, but not central, amygdala interfere with Pavlovian second-order conditioning and reinforcer devaluation effects. $J$. Neurosci. 16, 5256-5265.

Hesse, S., Müller, U., Lincke, T., Barthel, H., Villmann, T., Angermeyer, M. C., et al. (2005). Serotonin and dopamine transporter imaging in patients with obsessive-compulsive disorder. Psychiatry Res. 140, 63-72. doi: 10.1016/j. pscychresns.2005.07.002

Hiroi, N., and White, N. M. (1991). The lateral nucleus of the amygdala mediates expression of the amphetamine-produced conditioned place preference. $J$. Neurosci. 11, 2107-2116.

Hitchcock, J., and Davis, M. (1986). Lesions of the amygdala, but not of the cerebellum or red nucleus, block conditioned fear as measured with the potentiated startle paradigm. Behav. Neurosci. 100, 11-22. doi: 10.1037/07357044.100.1.11

Hnasko, T. S., Chuhma, N., Zhang, H., Goh, G. Y., Sulzer, D., Palmiter, R. D., et al. (2010). Vesicular glutamate transport promotes dopamine storage and glutamate corelease in vivo. Neuron 65, 643-656. doi: 10.1016/j.neuron.2010. 02.012

Hollerman, J. R., Tremblay, L., and Schultz, W. (2000). Involvement of basal ganglia and orbitofrontal cortex in goal-directed behavior. Prog. Brain Res. 126, 193-215. doi: 10.1016/s0079-6123(00)26015-9

Hoover, W. B., and Vertes, R. P. (2011). Projections of the medial orbital and ventral orbital cortex in the rat. J. Comp. Neurol. 519, 3766-3801. doi: 10. $1002 /$ cne. 22733

Houk, J. C., Adams, J. L., Barto, A. G. (1995). "A model of how the basal ganglia generate and use neural signals that predict reinforcement," in Models of Information Processing in the Basal Ganglia, eds J. C. Houk, J. L. Davis and D. G. Beiser (Cambridge: The MIT Press), 249-270.

Humphries, M. D., and Prescott, T. J. (2010). The ventral basal ganglia, a selection mechanism at the crossroads of space, strategy and reward. Prog. Neurobiol. 90, 385-417. doi: 10.1016/j.pneurobio.2009.11.003

Ikemoto, S. (2007). Dopamine reward circuitry: two projection systems from the ventral midbrain to the nucleus accumbens-olfactory tubercle complex. Brain Res. Rev. 56, 27-78. doi: 10.1016/j.brainresrev.2007. 05.004

Insel, T. R., and Winslow, J. T. (1992). Neurobiology of obsessive compulsive disorder. Psychiatr. Clin. North Am. 15, 813-824.

Janak, P. H., and Tye, K. M. (2015). From circuits to behaviour in the amygdala. Nature 517, 284-292. doi: 10.1038/nature14188

Joel, D. (2006). Current animal models of obsessive compulsive disorder: a critical review. Prog. Neuropsychopharmacol. Biol. Psychiatry 30, 374-388. doi: 10. 1016/j.pnpbp.2005.11.006 
Joel, D., Niv, Y., and Ruppin, E. (2002). Actor-critic models of the basal ganglia: new anatomical and computational perspectives. Neural Netw. 15, 535-547. doi: 10.1016/s0893-6080(02)00047-3

Joel, D., and Weiner, I. (2000). The connections of the dopaminergic system with the striatum in rats and primates: an analysis with respect to the functional and compartmental organization of the striatum. Neuroscience 96, 451-474. doi: 10. 1016/s0306-4522(99)00575-8

Kalivas, P. W., Volkow, N., and Seamans, J. (2005). Unmanageable motivation in addiction: a pathology in prefrontal-accumbens glutamate transmission. Neuron 45, 647-650. doi: 10.1016/j.neuron.2005.02.005

Karayiorgou, M., Altemus, M., Galke, B. L., Goldman, D., Murphy, D. L., Ott, J., et al. (1997). Genotype determining low catechol-O-methyltransferase activity as a risk factor for obsessive-compulsive disorder. Proc. Natl. Acad. Sci. U S A 94, 4572-4575. doi: 10.1073/pnas.94.9.4572

Karayiorgou, M., Sobin, C., Blundell, M. L., Galke, B. L., Malinova, L., Goldberg, P., et al. (1999). Family-based association studies support a sexually dimorphic effect of COMT and MAOA on genetic susceptibility to obsessive-compulsive disorder. Biol. Psychiatry 45, 1178-1189. doi: 10.1016/s0006-3223(98)00319-9

Kawaguchi, Y. (1997). Neostriatal cell subtypes and their functional roles. Neurosci. Res. 27, 1-8. doi: 10.1016/s0168-0102(96)01134-0

Kawaguchi, Y., Wilson, C. J., Augood, S. J., and Emson, P. C. (1995). Striatal interneurones: chemical, physiological and morphological characterization. Trends Neurosci. 18, 527-535. doi: 10.1016/0166-2236(95)98374-8

Kelley, A. E. (2004). Ventral striatal control of appetitive motivation: role in ingestive behavior and reward-related learning. Neurosci. Biobehav. Rev. 27, 765-776. doi: 10.1016/j.neubiorev.2003.11.015

Kelley, A. E., Domesick, V. B., and Nauta, W. J. (1982). The amygdalostriatal projection in the rat-an anatomical study by anterograde and retrograde tracing methods. Neuroscience 7, 615-630. doi: 10.1007/978-1-4684-7920-1_24

Killcross, S., and Coutureau, E. (2003). Coordination of actions and habits in the medial prefrontal cortex of rats. Cereb. Cortex 13, 400-408. doi: 10. 1093/cercor/13.4.400

Kim, J. J., Lee, M. C., Kim, J., Kim, I. Y., Kim, S. I., Han, M. H., et al. (2001). Grey matter abnormalities in obsessive-compulsive disorder: statistical parametric mapping of segmented magnetic resonance images. Br. J. Psychiatry 179, 330-334. doi: 10.1192/bjp.179.4.330

Klanker, M., Feenstra, M., and Denys, D. (2013). Dopaminergic control of cognitive flexibility in humans and animals. Front. Neurosci. 7:201. doi: 10. 3389/fnins.2013.00201

Knight, R. T. (2007). Neuroscience. Neural networks debunk phrenology. Science 316, 1578-1579. doi: 10.1126/science.1144677

Kravitz, A. V., Freeze, B. S., Parker, P. R., Kay, K., Thwin, M. T., Deisseroth, K., et al. (2010). Regulation of parkinsonian motor behaviours by optogenetic control of basal ganglia circuitry. Nature 466, 622-626. doi: 10 . 1038/nature09159

Kravitz, A. V., and Kreitzer, A. C. (2012). Striatal mechanisms underlying movement, reinforcement and punishment. Physiology (Bethesda) 27, 167-177. doi: 10.1152/physiol.00004.2012

Kreitzer, A. C. (2009). Physiology and pharmacology of striatal neurons. Annu. Rev. Neurosci. 32, 127-147. doi: 10.1146/annurev.neuro.051508. 135422

Krettek, J. E., and Price, J. L. (1977). Projections from the amygdaloid complex to the cerebral cortex and thalamus in the rat and cat. J. Comp. Neurol. 172, 687-722. doi: 10.1002/cne.901720408

Kringelbach, M. L., and Rolls, E. T. (2004). The functional neuroanatomy of the human orbitofrontal cortex: evidence from neuroimaging and neuropsychology. Prog. Neurobiol. 72, 341-372. doi: 10.1016/j.pneurobio.2004. 03.006

Kupchik, Y. M., Brown, R. M., Heinsbroek, J. A., Lobo, M. K., Schwartz, D. J., and Kalivas, P. W. (2015). Coding the direct/indirect pathways by D1 and D2 receptors is not valid for accumbens projections. Nat. Neurosci. 18, 1230-1232. doi: 10.1038/nn.4068

Lammel, S., Hetzel, A., Hackel, O., Jones, I., Liss, B., and Roeper, J. (2008). Unique properties of mesoprefrontal neurons within a dual mesocorticolimbic dopamine system. Neuron 57, 760-773. doi: 10.1016/j.neuron.2008.01.022

Lammel, S., Lim, B. K., and Malenka, R. C. (2014). Reward and aversion in a heterogeneous midbrain dopamine system. Neuropharmacology 76(Pt. B), 351-359. doi: 10.1016/j.neuropharm.2013.03.019
LeDoux, J. (2007). The amygdala. Curr. Biol. 17, R868-R874. doi: 10.1016/j.cub. 2007.08.005

LeDoux, J. E. (2000). Emotion circuits in the brain. Annu. Rev. Neurosci. 23, 155-184. doi: 10.1146/annurev.neuro.23.1.155

LeDoux, J. E. (2014). Coming to terms with fear. Proc. Natl. Acad. Sci. U S A 111, 2871-2878. doi: 10.1073/pnas.1400335111

LeDoux, J. E., Cicchetti, P., Xagoraris, A., and Romanski, L. M. (1990). The lateral amygdaloid nucleus: sensory interface of the amygdala in fear conditioning. $J$. Neurosci. 10, 1062-1069.

Leonard, C. M. (1969). The prefrontal cortex of the rat. I. Cortical projection of the mediodorsal nucleus. II. Efferent connections. Brain Res. 12, 321-343. doi: 10. 1016/0006-8993(69)90003-1

Levy, D. J., and Glimcher, P. W. (2012). The root of all value: a neural common currency for choice. Curr. Opin. Neurobiol. 22, 1027-1038. doi: 10.1016/j.conb. 2012.06.001

Lewin, A. B., Wu, M. S., McGuire, J. F., and Storch, E. A. (2014). Cognitive behavior therapy for obsessive-compulsive and related disorders. Psychiatr. Clin. North Am. 37, 415-445. doi: 10.1016/j.psc.2014.05.002

Likhtik, E., Stujenske, J. M., Topiwala, M. A., Harris, A. Z., and Gordon, J. A. (2014). Prefrontal entrainment of amygdala activity signals safety in learned fear and innate anxiety. Nat. Neurosci. 17, 106-113. doi: 10.1038/nn. 3582

Ljungberg, T., Apicella, P., and Schultz, W. (1992). Responses of monkey dopamine neurons during learning of behavioral reactions. J. Neurophysiol. 67, $145-163$.

Ludvik, D., Boschen, M. J., and Neumann, D. L. (2015). Effective behavioural strategies for reducing disgust in contamination-related OCD: a review. Clin. Psychol. Rev. doi: 10.1016/j.cpr.2015.07.001 [Epub ahead of print].

Mantione, M., Nieman, D., Figee, M., van den Munckhof, P., Schuurman, R., and Denys, D. (2015). Cognitive effects of deep brain stimulation in patients with obsessive-compulsive disorder. J. Psychiatry Neurosci. 40, 378-386. doi: 10. 1503/jpn.140210

Mar, A. C., Walker, A. L., Theobald, D. E., Eagle, D. M., and Robbins, T. W. (2011). Dissociable effects of lesions to orbitofrontal cortex subregions on impulsive choice in the rat. J. Neurosci. 31, 6398-6404. doi: 10.1523/JNEUROSCI.662010.2011

Marsh, R., Tau, G. Z., Wang, Z., Huo, Y., Liu, G., Hao, X., et al. (2015). Rewardbased spatial learning in unmedicated adults with obsessive-compulsive disorder. Am. J. Psychiatry 172, 383-392. doi: 10.1176/appi.ajp.2014.13 121700

Mataix-Cols, D., Rosario-Campos, M. C., and Leckman, J. F. (2005). A multidimensional model of obsessive-compulsive disorder. Am. J. Psychiatry 162, 228-238. doi: 10.1176/appi.ajp.162.2.228

Mataix-Cols, D., Wooderson, S., Lawrence, N., Brammer, M. J., Speckens, A., and Phillips, M. L. (2004). Distinct neural correlates of washing, checking and hoarding symptom dimensions in obsessive-compulsive disorder. Arch. Gen. Psychiatry 61, 564-576. doi: 10.1001/archpsyc.61.6.564

McCracken, C. B., and Grace, A. A. (2007). High-frequency deep brain stimulation of the nucleus accumbens region suppresses neuronal activity and selectively modulates afferent drive in rat orbitofrontal cortex in vivo. J. Neurosci. 27, 12601-12610. doi: 10.1523/jneurosci.3750-07.2007

McCutcheon, J. E., Beeler, J. A., and Roitman, M. F. (2012). Sucrose-predictive cues evoke greater phasic dopamine release than saccharin-predictive cues. Synapse 66, 346-351. doi: 10.1002/syn.21519

McDougle, C. J., Epperson, C. N., Pelton, G. H., Wasylink, S., and Price, L. H. (2000). A double-blind, placebo-controlled study of risperidone addition in serotonin reuptake inhibitor-refractory obsessive-compulsive disorder. Arch. Gen. Psychiatry 57, 794-801. doi: 10.1001/archpsyc.57.8.794

McFall, M., and Wollersheim, J. (1979). Obsessive-compulsive neurosis: a cognitive-behavioral formulation and approach to treatment. Cogn. Ther. Res. 3, 333-348. doi: 10.1007/bf01184447

McGinty, V. B., and Grace, A. A. (2009). Timing-dependent regulation of evoked spiking in nucleus accumbens neurons by integration of limbic and prefrontal cortical inputs. J. Neurophysiol. 101, 1823-1835. doi: 10.1152/jn.91162.2008

McLaughlin, N. C., Strong, D., Abrantes, A., Garnaat, S., Cerny, A., O’Connell, C., et al. (2015). Extinction retention and fear renewal in a lifetime obsessivecompulsive disorder sample. Behav. Brain Res. 280, 72-77. doi: 10.1016/j.bbr. 2014.11.011 
Menzies, L., Chamberlain, S. R., Laird, A. R., Thelen, S. M., Sahakian, B. J., and Bullmore, E. T. (2008). Integrating evidence from neuroimaging and neuropsychological studies of obsessive-compulsive disorder: the orbitofrontostriatal model revisited. Neurosci. Biobehav. Rev. 32, 525-549. doi: 10.1016/j. neubiorev.2007.09.005

Meredith, G. E. (1999). The synaptic framework for chemical signaling in nucleus accumbens. Ann. N Y Acad. Sci. 877, 140-156. doi: 10.1111/j.1749-6632.1999. tb09266.x

Milad, M. R., Furtak, S. C., Greenberg, J. L., Keshaviah, A., Im, J. J., Falkenstein, M. J., et al. (2013). Deficits in conditioned fear extinction in obsessivecompulsive disorder and neurobiological changes in the fear circuit. JAMA Psychiatry 70, 608-618; quiz 554. doi: 10.1001/jamapsychiatry.2013.914

Milad, M. R., and Rauch, S. L. (2012). Obsessive-compulsive disorder: beyond segregated cortico-striatal pathways. Trends Cogn. Sci. 16, 43-51. doi: 10.1016/j. tics.2011.11.003

Mogenson, G., Jones, D., and Yim, C. (1980). From motivation to action: functional interface between the limbic system and the motor system. Prog. Neurobiol. 14, 69-97. doi: 10.1016/0301-0082(80)90018-0

Moghaddam, B., and Wood, J. (2014). Team work matters: coordinated neuronal activity in brain systems relevant to psychiatric disorders. JAMA Psychiarty 71, 197-199. doi: 10.1001/jamapsychiatry.2013.2080

Molloy, A. G., and Waddington, J. L. (1987). Pharmacological characterization in the rat of grooming and other behavioural responses to the D1 dopamine receptor agonist R-SK\&F 38393. J. Psychopharmacol. 1, 177-183. doi: 10. $1177 / 026988118700100304$

Montague, P. R., Dayan, P., and Sejnowski, T. J. (1996). A framework for mesencephalic dopamine systems based on predictive Hebbian learning. J. Neurosci. 16, 1936-1947.

Monteiro, P., and Feng, G. (2015). Learning from animal models of obsessivecompulsive disorder. Biol. Psychiatry doi: 10.1016/j.biopsych.2015.04.020 [Epub ahead of print].

Morris, G., Nevet, A., Arkadir, D., Vaadia, E., and Bergman, H. (2006). Midbrain dopamine neurons encode decisions for future action. Nat. Neurosci. 9, 1057-1063. doi: 10.1038/nn1743

Morrison, S. E., and Salzman, C. D. (2010). Re-valuing the amygdala. Curr. Opin. Neurobiol. 20, 221-230. doi: 10.1016/j.conb.2010.02.007

Mundt, A., Klein, J., Joel, D., Heinz, A., Djodari-Irani, A., Harnack, D., et al. (2009). High-frequency stimulation of the nucleus accumbens core and shell reduces quinpirole-induced compulsive checking in rats. Eur. J. Neurosci. 29, 2401-2412. doi: 10.1111/j.1460-9568.2009.06777.x

Murphy, D. L., Moya, P. R., Fox, M. A., Rubenstein, L. M., Wendland, J. R., and Timpano, K. R. (2013). Anxiety and affective disorder comorbidity related to serotonin and other neurotransmitter systems: obsessive-compulsive disorder as an example of overlapping clinical and genetic heterogeneity. Philos. Trans. R. Soc. Lond. B Biol. Sci. 368:20120435. doi: 10.1098/rstb. 2012.0435

Murschall, A., and Hauber, W. (2006). Inactivation of the ventral tegmental area abolished the general excitatory influence of Pavlovian cues on instrumental performance. Learn. Mem. 13, 123-126. doi: 10.1101/lm.127106

Nader, K., Majidishad, P., Amorapanth, P., and LeDoux, J. E. (2001). Damage to the lateral and central, but not other, amygdaloid nuclei prevents the acquisition of auditory fear conditioning. Learn. Mem. 8, 156-163. doi: 10. 1101/lm.38101

Nair-Roberts, R. G., Chatelain-Badie, S. D., Benson, E., White-Cooper, H., Bolam, J. P., and Ungless, M. A. (2008). Stereological estimates of dopaminergic, GABAergic and glutamatergic neurons in the ventral tegmental area, substantia nigra and retrorubral field in the rat. Neuroscience 152, 1024-1031. doi: 10. 1016/j.neuroscience.2008.01.046

Nakamae, T., Sakai, Y., Abe, Y., Nishida, S., Fukui, K., Yamada, K., et al. (2014). Altered fronto-striatal fiber topography and connectivity in obsessivecompulsive disorder. PLoS One 9:e112075. doi: 10.1371/journal.pone.0112075

Nakao, T., Nakagawa, A., Yoshiura, T., Nakatani, E., Nabeyama, M., Yoshizato, C., et al. (2005). Brain activation of patients with obsessive-compulsive disorder during neuropsychological and symptom provocation tasks before and after symptom improvement: a functional magnetic resonance imaging study. Biol. Psychiatry 57, 901-910. doi: 10.1016/j.biopsych.2004.12.039

Narayanaswamy, J. C., Jose, D., Kalmady, S., Venkatasubramanian, G., and Reddy, Y. C. (2013). Clinical correlates of nucleus accumbens volume in drug-naive, adult patients with obsessive-compulsive disorder. Aust. N Z J. Psychiatry 47, 930-937. doi: 10.1177/0004867413491153

Nestadt, G., Addington, A., Samuels, J., Liang, K. Y., Bienvenu, O. J., Riddle, M., et al. (2003). The identification of OCD-related subgroups based on comorbidity. Biol. Psychiatry 53, 914-920. doi: 10.1016/s0006-3223(02) 01677-3

Nestadt, G., Samuels, J., Riddle, M. A., Liang, K. Y., Bienvenu, O. J., Hoehn-Saric, R., et al. (2001). The relationship between obsessive-compulsive disorder and anxiety and affective disorders: results from the Johns Hopkins OCD Family Study. Psychol. Med. 31, 481-487. doi: 10.1017/s0033291701003579

Nicola, S. M., Surmeier, J., and Malenka, R. C. (2000). Dopaminergic modulation of neuronal excitability in the striatum and nucleus accumbens. Annu. Rev. Neurosci. 23, 185-215. doi: 10.1146/annurev.neuro.23.1.185

Niehaus, D. J., Kinnear, C. J., Corfield, V. A., du Toit, P. L., van Kradenburg, J., Moolman-Smook, J. C., et al. (2001). Association between a catecholo-methyltransferase polymorphism and obsessive-compulsive disorder in the Afrikaner population. J. Affect. Disord. 65, 61-65. doi: 10.1016/s01650327(00)00246-9

Nikolaus, S., Antke, C., Beu, M., and Muller, H. W. (2010). Cortical GABA, striatal dopamine and midbrain serotonin as the key players in compulsive and anxiety disorders-results from in vivo imaging studies. Rev. Neurosci. 21, 119-139. doi: 10.1515/revneuro.2010.21.2.119

Noonan, M. P., Kolling, N., Walton, M. E., and Rushworth, M. F. (2012). Reevaluating the role of the orbitofrontal cortex in reward and reinforcement. Eur. J. Neurosci. 35, 997-1010. doi: 10.1111/j.1460-9568.2012.08023.x

Noonan, M. P., Walton, M. E., Behrens, T. E., Sallet, J., Buckley, M. J., and Rushworth, M. F. (2010). Separate value comparison and learning mechanisms in macaque medial and lateral orbitofrontal cortex. Proc. Natl. Acad. Sci. U S A 107, 20547-20552. doi: 10.1073/pnas.1012246107

Nutt, D., and Malizia, A. (2006). Anxiety and OCD - the chicken or the egg? J. Psychopharmacol. 20, 729-731. doi: 10.1177/02698811060 68424

Oades, R. D., and Halliday, G. M. (1987). Ventral tegmental (A10) system: neurobiology. Brain Res. 434, 117-165. doi: 10.1016/0165-0173(87)90011-7

O'Donnell, P., Lavin, A., Enquist, L. W., Grace, A. A., and Card, J. P. (1997). Interconnected parallel circuits between rat nucleus accumbens and thalamus revealed by retrograde transynaptic transport of pseudorabies virus. J. Neurosci. 17, 2143-2167.

Omelchenko, N., and Sesack, S. R. (2009). Ultrastructural analysis of local collaterals of rat ventral tegmental area neurons: GABA phenotype and synapses onto dopamine and GABA cells. Synapse 63, 895-906. doi: 10 1002/syn.20668

Ongur, D., and Price, J. L. (2000). The organization of networks within the orbital and medial prefrontal cortex of rats, monkeys and humans. Cereb. Cortex 10 , 206-219. doi: 10.1093/cercor/10.3.206

Ooms, P., Blankers, M., Figee, M., Mantione, M., van den Munckhof, P., Schuurman, P. R., et al. (2014). Rebound of affective symptoms following acute cessation of deep brain stimulation in obsessive-compulsive disorder. Brain Stimul. 7, 727-731. doi: 10.1016/j.brs.2014.06.009

Ostlund, S., and Balleine, B. (2007a). Orbitofrontal cortex mediates outcome encoding in Pavlovian but not instrumental conditioning. J. Neurosci. 27, 4819-4825. doi: 10.1523/jneurosci.5443-06.2007

Ostlund, S. B., and Balleine, B. W. (2007b). The contribution of orbitofrontal cortex to action selection. Ann. N Y Acad. Sci. 1121, 174-192. doi: 10 1196/annals.1401.033

Parkinson, J. A., Cardinal, R. N., and Everitt, B. J. (2000). Limbic corticalventral striatal systems underlying appetitive conditioning. Prog. Brain Res 126, 263-285. doi: 10.1016/s0079-6123(00)26019-6

Parkinson, J. A., Dalley, J. W., Cardinal, R. N., Bamford, A., Fehnert, B., Lachenal, G., et al. (2002). Nucleus accumbens dopamine depletion impairs both acquisition and performance of appetitive Pavlovian approach behaviour: implications for mesoaccumbens dopamine function. Behav. Brain Res. 137, 149-163. doi: 10.1016/s0166-4328(02)00291-7

Parkinson, J. A., Olmstead, M. C., Burns, L. H., Robbins, T. W., and Everitt, B. J. (1999). Dissociation in the effects of lesions of the nucleus accumbens core and shell in appetitive Pavlovian approach behavior and the potentiation of conditioned reinforcement and locomotor activity by d-amphetamine. $J$. Neurosci. 19, 2401-2411. 
Paton, J. J., Belova, M. A., Morrison, S. E., and Salzman, C. D. (2006). The primate amygdala represents the positive and negative value of visual stimuli during learning. Nature 439, 865-870. doi: 10.1038/nature04490

Pauls, D. L., Abramovitch, A., Rauch, S. L., and Geller, D. A. (2014). Obsessivecompulsive disorder: an integrative genetic and neurobiological perspective. Nat. Rev. Neurosci. 15, 410-424. doi: 10.1038/nrn3746

Pennartz, C. M., Groenewegen, H. J., and Lopes da Silva, F. H. (1994). The nucleus accumbens as a complex of functionally distinct neuronal ensembles: an integration of behavioural, electrophysiological and anatomical data. Prog. Neurobiol. 42, 719-761. doi: 10.1016/0301-0082(94) 90025-6

Peoples, L. L., and West, M. O. (1996). Phasic firing of single neurons in the rat nucleus accumbens correlated with the timing of intravenous cocaine selfadministration. J. Neurosci. 16, 3459-3473.

Phillips, P. E., Stuber, G. D., Heien, M. L., Wightman, R. M., and Carelli, R. M. (2003). Subsecond dopamine release promotes cocaine seeking. Nature 422, 614-618. doi: 10.1038/nature01476

Piantadosi, S. C., and Ahmari, S. E. (2015). Using optogenetics to dissect the neural circuits underlying OCD and related disorders. Curr. Treat. Options Psychiatry 2, 297-311. doi: 10.1007/s40501-015-0056-3

Pinto, A., Eisen, J. L., Mancebo, M. C., Greenberg, B. D., Stout, R. L., and Rasmussen, S. A. (2007). Taboo thoughts and doubt/checking: a refinement of the factor structure for obsessive-compulsive disorder symptoms. Psychiatry Res. 151, 255-258. doi: 10.1016/j.psychres.2006.09.005

Pitkänen, A., Savander, V., and LeDoux, J. E. (1997). Organization of intraamygdaloid circuitries in the rat: an emerging framework for understanding functions of the amygdala. Trends Neurosci. 20, 517-523. doi: 10.1016/s01662236(97)01125-9

Posner, J., Marsh, R., Maia, T. V., Peterson, B. S., Gruber, A., and Simpson, H. B. (2014). Reduced functional connectivity within the limbic cortico-striato-thalamo-cortical loop in unmedicated adults with obsessivecompulsive disorder. Hum. Brain Mapp. 35, 2852-2860. doi: 10.1002/hbm. 22371

Price, J. L. (2007). Definition of the orbital cortex in relation to specific connections with limbic and visceral structures and other cortical regions. Ann. N Y Acad. Sci. 1121, 54-71. doi: 10.1196/annals.1401.008

Pujol, J., Soriano-Mas, C., Alonso, P., Cardoner, N., Menchón, J. M., Deus, J., et al. (2004). Mapping structural brain alterations in obsessive-compulsive disorder. Arch. Gen. Psychiatry 61, 720-730. doi: 10.1001/archpsyc.61.7.720

Rachman, S. (1997). A cognitive theory of obsessions. Behav. Res. Ther. 35, 793-802. doi: 10.1016/s0005-7967(97)00040-5

Rauch, S. L., Jenike, M. A., Alpert, N. M., Baer, L., Breiter, H. C., Savage, C. R., et al. (1994). Regional cerebral blood flow measured during symptom provocation in obsessive-compulsive disorder using oxygen 15-labeled carbon dioxide and positron emission tomography. Arch. Gen. Psychiatry 51, 62-70. doi: 10.1001/archpsyc. 1994.03950010062008

Remijnse, P. L., Nielen, M. M., van Balkom, A. J., Cath, D. C., van Oppen, P., Uylings, H. B., et al. (2006). Reduced orbitofrontal-striatal activity on a reversal learning task in obsessive-compulsive disorder. Arch. Gen. Psychiatry 63, 1225-1236. doi: 10.1001/archpsyc.63.11. 1225

Robbins, T. W., and Everitt, B. J. (2002). Limbic-striatal memory systems and drug addiction. Neurobiol. Learn. Mem. 78, 625-636. doi: 10.1006/nlme.2002. 4103

Rodriguez-Romaguera, J., Do-Monte, F. H., Tanimura, Y., Quirk, G. J., and Haber, S. N. (2015). Enhancement of fear extinction with deep brain stimulation: evidence for medial orbitofrontal involvement. Neuropsychopharmacology 40, 1726-1733. doi: 10.1038/npp.2015.20

Roesch, M. R., Calu, D. J., and Schoenbaum, G. (2007). Dopamine neurons encode the better option in rats deciding between differently delayed or sized rewards. Nat. Neurosci. 10, 1615-1624. doi: 10.1038/nn2013

Roitman, M. F., Stuber, G. D., Phillips, P. E., Wightman, R. M., and Carelli, R. M. (2004). Dopamine operates as a subsecond modulator of food seeking. J. Neurosci. 24, 1265-1271. doi: 10.1523/jneurosci.3823-03.2004

Roitman, M. F., Wheeler, R. A., and Carelli, R. M. (2005). Nucleus accumbens neurons are innately tuned for rewarding and aversive taste stimuli, encode their predictors and are linked to motor output. Neuron 45, 587-597. doi: 10. 1016/j.neuron.2004.12.055
Roitman, M. F., Wheeler, R. A., Wightman, R. M., and Carelli, R. M. (2008). Real-time chemical responses in the nucleus accumbens differentiate rewarding and aversive stimuli. Nat. Neurosci. 11, 1376-1377. doi: 10.1038/nn. 2219

Rose, J. E., and Woolsey, C. N. (1948). The orbitofrontal cortex and its connections with the mediodorsal nucleus in rabbit, sheep and cat. Res. Publ. Assoc. Res. Nerv. Ment. Dis. 27, 210-232.

Rotge, J. Y., Guehl, D., Dilharreguy, B., Tignol, J., Bioulac, B., Allard, M., et al. (2009). Meta-analysis of brain volume changes in obsessive-compulsive disorder. Biol. Psychiatry 65, 75-83. doi: 10.1016/j.biopsych.2008.06.019

Rudebeck, P. H., and Murray, E. A. (2011). Balkanizing the primate orbitofrontal cortex: distinct subregions for comparing and contrasting values. Ann. N Y Acad. Sci. 1239, 1-13. doi: 10.1111/j.1749-6632.2011.06267.x

Rudebeck, P. H., and Murray, E. A. (2014). The orbitofrontal oracle: cortical mechanisms for the prediction and evaluation of specific behavioral outcomes. Neuron 84, 1143-1156. doi: 10.1016/j.neuron.2014.10.049

Russo, S. J., Dietz, D. M., Dumitriu, D., Morrison, J. H., Malenka, R. C., and Nestler, E. J. (2010). The addicted synapse: mechanisms of synaptic and structural plasticity in nucleus accumbens. Trends Neurosci. 33, 267-276. doi: 10.1016/j.tins.2010.02.002

Sakai, Y., Narumoto, J., Nishida, S., Nakamae, T., Yamada, K., Nishimura, T., et al. (2011). Corticostriatal functional connectivity in non-medicated patients with obsessive-compulsive disorder. Eur. Psychiatry 26, 463-469. doi: 10.1016/j. eurpsy.2010.09.005

Salamone, J. D., and Correa, M. (2002). Motivational views of reinforcement: implications for understanding the behavioral functions of nucleus accumbens dopamine. Behav. Brain Res. 137, 3-25. doi: 10.1016/s0166-4328(02)00282-6

Salamone, J. D., Correa, M., Farrar, A., and Mingote, S. M. (2007). Effort-related functions of nucleus accumbens dopamine and associated forebrain circuits. Psychopharmacology (Berl) 191, 461-482. doi: 10.1007/s00213-006-0668-9

Sanchez-Catalan, M. J., Kaufling, J., Georges, F., Veinante, P., and Barrot, M. (2014). The antero-posterior heterogeneity of the ventral tegmental area. Neuroscience 282C, 198-216. doi: 10.1016/j.neuroscience.2014.09.025

Saxena, S., Bota, R. G., and Brody, A. L. (2001). Brain-behavior relationships in obsessive-compulsive disorder. Semin. Clin. Neuropsychiatry 6, 82-101. doi: 10. 1053/scnp.2001.21833

Saxena, S., Brody, A. L., Ho, M. L., Alborzian, S., Maidment, K. M., Zohrabi, N., et al. (2002). Differential cerebral metabolic changes with paroxetine treatment of obsessive-compulsive disorder vs major depression. Arch. Gen. Psychiatry 59, 250-261. doi: 10.1001/archpsyc.59.3.250

Saxena, S., Brody, A. L., Maidment, K. M., Dunkin, J. J., Colgan, M., Alborzian, S., et al. (1999). Localized orbitofrontal and subcortical metabolic changes and predictors of response to paroxetine treatment in obsessive-compulsive disorder. Neuropsychopharmacology 21, 683-693. doi: 10.1016/s0893$133 \mathrm{x}(99) 00082-2$

Schilman, E. A., Uylings, H. B., Galis-de Graaf, Y., Joel, D., and Groenewegen, H. J. (2008). The orbital cortex in rats topographically projects to central parts of the caudate-putamen complex. Neurosci. Lett. 432, 40-45. doi: 10.1016/j.neulet. 2007.12.024

Schindler, K. M., Richter, M. A., Kennedy, J. L., Pato, M. T., and Pato, C. N. (2000). Association between homozygosity at the COMT gene locus and obsessive compulsive disorder. Am. J. Med. Genet. 96, 721-724. doi: 10.1002/10968628(20001204)96:6<721::aid-ajmg4>3.0.co;2-m

Schoenbaum, G., Chiba, A., and Gallagher, M. (1999). Neural encoding in orbitofrontal cortex and basolateral amygdala during olfactory discrimination learning. J. Neurosci. 19, 1876-1884.

Schultz, W. (1998). Predictive reward signal of dopamine neurons. J. Neurophysiol. $80,1-27$.

Schultz, W., Apicella, P., and Ljungberg, T. (1993). Responses of monkey dopamine neurons to reward and conditioned stimuli during successive steps of learning a delayed response task. J. Neurosci. 13, 900-913.

Schultz, W., Dayan, P., and Montague, P. R. (1997). A neural substrate of prediction and reward. Science 275, 1593-1599. doi: 10.1126/science.275.5306. 1593

Sesack, S. R., and Grace, A. A. (2010). Cortico-Basal Ganglia reward network: microcircuitry. Neuropsychopharmacology 35, 27-47. doi: 10.1038/npp.2009.93

Setlow, B., Holland, P. C., and Gallagher, M. (2002). Disconnection of the basolateral amygdala complex and nucleus accumbens impairs appetitive 
pavlovian second-order conditioned responses. Behav. Neurosci. 116, 267-275. doi: 10.1037/0735-7044.116.2.267

Setlow, B., Schoenbaum, G., and Gallagher, M. (2003). Neural encoding in ventral striatum during olfactory discrimination learning. Neuron 38, 625-636. doi: 10. 1016/s0896-6273(03)00264-2

Shiflett, M. W., and Balleine, B. W. (2010). At the limbic-motor interface: disconnection of basolateral amygdala from nucleus accumbens core and shell reveals dissociable components of incentive motivation. Eur. J. Neurosci. 32, 1735-1743. doi: 10.1111/j.1460-9568.2010.07439.x

Siegel, M., Donner, T. H., and Engel, A. K. (2012). Spectral fingerprints of large-scale neuronal interactions. Nat. Rev. Neurosci. 13, 121-134. doi: 10. 1038/nrn3137

Simon, D., Adler, N., Kaufmann, C., and Kathmann, N. (2014). Amygdala hyperactivation during symptom provocation in obsessive-compulsive disorder and its modulation by distraction. Neuroimage Clin. 4, 549-557. doi: 10.1016/j.nicl.2014.03.011

Simon, D., Kaufmann, C., Müsch, K., Kischkel, E., and Kathmann, N. (2010). Fronto-striato-limbic hyperactivation in obsessive-compulsive disorder during individually tailored symptom provocation. Psychophysiology 47, 728-738. doi: 10.1111/j.1469-8986.2010.00980.x

Simpson, H., Foa, E. B., Liebowitz, M. R., Huppert, J. D., Cahill, S., Maher, M. J., et al. (2013). Cognitive-behavioral therapy vs risperidone for augmenting serotonin reuptake inhibitors in obsessive-compulsive disorder: a randomized clinical trial. JAMA Psychiatry 70, 1190-1199. doi: 10.1001/jamapsychiatry. 2013.1932

Singer, W., and Gray, C. M. (1995). Visual feature integration and the temporal correlation hypothesis. Annu. Rev. Neurosci. 18, 555-586. doi: 10. 1146/annurev.neuro.18.1.555

Sjoerds, Z., Luigjes, J., van den Brink, W., Denys, D., and Yücel, M. (2014). The role of habits and motivation in human drug addiction: a reflection. Front. Psychiatry 5:8. doi: 10.3389/fpsyt.2014.00008

Stein, D. J., Arya, M., Pietrini, P., Rapoport, J. L., and Swedo, S. E. (2006). Neurocircuitry of disgust and anxiety in obsessive-compulsive disorder: a positron emission tomography study. Metab. Brain Dis. 21, 267-277. doi: 10. 1007/s11011-006-9021-6

Stein, D. J., Fineberg, N. A., Bienvenu, O. J., Denys, D., Lochner, C., Nestadt, G., et al. (2010). Should OCD be classified as an anxiety disorder in DSM-V? Depress. Anxiety 27, 495-506. doi: 10.1002/da.20699

Stopper, C. M., Green, E. B., and Floresco, S. B. (2014). Selective involvement by the medial orbitofrontal cortex in biasing risky, but not impulsive, choice. Cereb. Cortex 24, 154-162. doi: 10.1093/cercor/bhs 297

Stuber, G. D., Hnasko, T. S., Britt, J. P., Edwards, R. H., and Bonci, A. (2010). Dopaminergic terminals in the nucleus accumbens but not the dorsal striatum corelease glutamate. J. Neurosci. 30, 8229-8233. doi: 10.1523/JNEUROSCI. 1754-10.2010

Stuber, G. D., Roitman, M. F., Phillips, P. E., Carelli, R. M., and Wightman, R. M. (2005). Rapid dopamine signaling in the nucleus accumbens during contingent and noncontingent cocaine administration. Neuropsychopharmacology 30, 853-863. doi: 10.1038/sj.npp.1300619

Stuber, G. D., Sparta, D. R., Stamatakis, A. M., van Leeuwen, W. A., Hardjoprajitno, J. E., Cho, S., et al. (2011). Excitatory transmission from the amygdala to nucleus accumbens facilitates reward seeking. Nature 475, 377-380. doi: 10.1038/nature10194

Sturm, V., Lenartz, D., Koulousakis, A., Treuer, H., Herholz, K., Klein, J. C., et al. (2003). The nucleus accumbens: a target for deep brain stimulation in obsessive-compulsive- and anxiety-disorders. J. Chem. Neuroanat. 26, 293-299. doi: 10.1016/j.jchemneu.2003.09.003

Subramaniam, M., Soh, P., Vaingankar, J. A., Picco, L., and Chong, S. A. (2013). Quality of life in obsessive-compulsive disorder: impact of the disorder and of treatment. CNS Drugs 27, 367-383. doi: 10.1007/s40263-013-0056-Z

Swanson, L. (1982). The projection of the ventral tegmental area and adjacent regions: a combined fluorescent retrograde tracer and immunofluorescence study in the rat. Brain Res. Bull. 9, 321-353. doi: 10.1016/0361-9230(82) 90145-9

Swedo, S. E., Pietrini, P., Leonard, H. L., Schapiro, M. B., Rettew, D. C., Goldberger, E. L., et al. (1992). Cerebral glucose metabolism in childhood-onset obsessivecompulsive disorder. Arch. Gen. Psychiatry 49, 690-694. doi: 10.1001/archpsyc. 1992.01820090018003
Swedo, S. E., Schapiro, M. B., Grady, C. L., Cheslow, D. L., Leonard, H. L., Kumar, A., et al. (1989). Cerebral glucose metabolism in childhood-onset obsessivecompulsive disorder. Arch. Gen. Psychiatry 46, 518-523. doi: 10.1001/archpsyc. 1989.01810060038007

Szeszko, P. R., Robinson, D., Alvir, J. M., Bilder, R. M., Lencz, T., Ashtari, M., et al. (1999). Orbital frontal and amygdala volume reductions in obsessivecompulsive disorder. Arch. Gen. Psychiatry 56, 913-919. doi: 10.1001/archpsyc. 56.10 .913

Tass, P. A., Klosterkötter, J., Schneider, F., Lenartz, D., Koulousakis, A., and Sturm, V. (2003). Obsessive-compulsive disorder: development of demandcontrolled deep brain stimulation with methods from stochastic phase resetting. Neuropsychopharmacology 1(Suppl. 28), S27-S34. doi: 10.1038/sj. npp. 1300144

Tepper, J. M., and Bolam, J. P. (2004). Functional diversity and specificity of neostriatal interneurons. Curr. Opin. Neurobiol. 14, 685-692. doi: 10.1016/j. conb.2004.10.003

Tritsch, N. X., Ding, J. B., and Sabatini, B. L. (2012). Dopaminergic neurons inhibit striatal output through non-canonical release of GABA. Nature 490, 262-266. doi: 10.1038/nature11466

Tye, K. M., Prakash, R., Kim, S. Y., Fenno, L. E., Grosenick, L., Zarabi, H., et al. (2011). Amygdala circuitry mediating reversible and bidirectional control of anxiety. Nature 471, 358-362. doi: 10.1038/nature09820

Uylings, H. B., Groenewegen, H. J., and Kolb, B. (2003). Do rats have a prefrontal cortex? Behav. Brain Res. 146, 3-17. doi: 10.1016/j.bbr.2003.09.028

Van Bockstaele, E. J., and Pickel, V. M. (1995). GABA-containing neurons in the ventral tegmental area project to the nucleus accumbens in rat brain. Brain Res. 682, 215-221. doi: 10.1016/0006-8993(95)00334-m

van den Heuvel, O. A., Veltman, D. J., Groenewegen, H. J., Dolan, R. J., Cath, D. C., Boellaard, R., et al. (2004). Amygdala activity in obsessive-compulsive disorder with contamination fear: a study with oxygen-15 water positron emission tomography. Psychiatry Res. 132, 225-237. doi: 10.1016/j.pscychresns.2004.06. 007

van der Wee, N. J., Stevens, H., Hardeman, J. A., Mandl, R. C., Denys, D. A., van Megen, H. J., et al. (2004). Enhanced dopamine transporter density in psychotropic-naive patients with obsessive-compulsive disorder shown by [123I]beta-CIT SPECT. Am. J. Psychiatry 161, 2201-2206. doi: 10.1176/appi. ajp.161.12.2201

Via, E., Cardoner, N., Pujol, J., Alonso, P., López-Solà, M., Real, E., et al. (2014). Amygdala activation and symptom dimensions in obsessive-compulsive disorder. Br. J. Psychiatry 204, 61-68. doi: 10.1192/bjp.bp.112.123364

Volman, S. F., Lammel, S., Margolis, E. B., Kim, Y., Richard, J. M., Roitman, M. F., et al. (2013). New insights into the specificity and plasticity of reward and aversion encoding in the mesolimbic system. J. Neurosci. 33, 17569-17576. doi: 10.1523/JNEUROSCI.3250-13.2013

Voorn, P., Vanderschuren, L. J., Groenewegen, H. J., Robbins, T. W., and Pennartz, C. M. (2004). Putting a spin on the dorsal-ventral divide of the striatum. Trends Neurosci. 27, 468-474. doi: 10.1016/j.tins.2004.06.006

Waelti, P., Dickinson, A., and Schultz, W. (2001). Dopamine responses comply with basic assumptions of formal learning theory. Nature 412, 43-48. doi: 10 . $1038 / 35083500$

Wheeler, R. A., and Carelli, R. M. (2009). Dissecting motivational circuitry to understand substance abuse. Neuropharmacology 56(Suppl. 1), 149-159. doi: 10.1016/j.neuropharm.2008.06.028

White, F. J., Bednarz, L. M., Wachtel, S. R., Hjorth, S., and Brooderson, R. J. (1988). Is stimulation of both D1 and D2 receptors necessary for the expression of dopamine-mediated behaviors? Pharmacol. Biochem. Behav. 30, 189-193. doi: 10.1016/0091-3057(88)90442-x

Whiteside, S. P., Port, J. D., and Abramowitz, J. S. (2004). A meta-analysis of functional neuroimaging in obsessive-compulsive disorder. Psychiatry Res. 132, 69-79. doi: 10.1016/j.pscychresns.2004.07.001

Wise, R. A. (2004). Dopamine, learning and motivation. Nat. Rev. Neurosci. 5, 483-494. doi: 10.1038/nrn1406

Woolley, J., Heyman, I., Brammer, M., Frampton, I., McGuire, P. K., and Rubia, K. (2008). Brain activation in paediatric obsessive compulsive disorder during tasks of inhibitory control. Br. J. Psychiatry 192, 25-31. doi: 10.1192/bjp.bp.107. 036558

Wright, C. I., Beijer, A. V., and Groenewegen, H. J. (1996). Basal amygdaloid complex afferents to the rat nucleus accumbens are compartmentally 
organized. J. Neurosci. 16, 1877-1893. doi: 10.1016/0306-4522(95) 00592-7

Wyvell, C., and Berridge, K. (2000). Intra-accumbens amphetamine increases the conditioned incentive salience of sucrose reward: enhancement of reward "wanting" without enhanced "liking" or response reinforcement. J. Neurosci. 20, 8122-8130.

Xu, M., Kobets, A., Du, J. C., Lennington, J., Li, L., Banasr, M., et al. (2015). Targeted ablation of cholinergic interneurons in the dorsolateral striatum produces behavioral manifestations of Tourette syndrome. Proc. Natl. Acad. Sci. U S A 112, 893-898. doi: 10.1073/pnas.1419533112

Yamaguchi, T., Sheen, W., and Morales, M. (2007). Glutamatergic neurons are present in the rat ventral tegmental area. Eur. J. Neurosci. 25, 106-118. doi: 10. $1111 /$ j.1460-9568.2006.05263.x

Yamaguchi, T., Wang, H. L., Li, X., Ng, T. H., and Morales, M. (2011). Mesocorticolimbic glutamatergic pathway. J. Neurosci. 31, 8476-8490. doi: 10. 1523/JNEUROSCI.1598-11.2011

Yin, H. H., and Knowlton, B. J. (2006). The role of the basal ganglia in habit formation. Nat. Rev. Neurosci. 7, 464-476. doi: 10.1038/nrn1919

Yin, H., Knowlton, B., and Balleine, B. W. (2006). Inactivation of dorsolateral striatum enhances sensitivity to changes in the action-outcome contingency in instrumental conditioning. Behav. Brain Res. 166, 189-196. doi: 10.1016/j.bbr. 2005.07.012

Yin, H. H., Ostlund, S. B., and Balleine, B. W. (2008). Reward-guided learning beyond dopamine in the nucleus accumbens: the integrative functions of cortico-basal ganglia networks. Eur. J. Neurosci. 28, 1437-1448. doi: 10.1111/j. 1460-9568.2008.06422.x
Yin, H., Ostlund, S., Knowlton, B., and Balleine, B. (2005). The role of the dorsomedial striatum in instrumental conditioning. Eur. J. Neurosci. 22, 513-523. doi: 10.1111/j.1460-9568.2005.04218.x

Zahm, D. S., and Brog, J. S. (1992). On the significance of subterritories in the “accumbens" part of the rat ventral striatum. Neuroscience 50, 751-767. doi: 10 1016/0306-4522(92)90202-d

Zald, D. H., and Rauch, S. L. (2006). The Orbitofrontal Cortex. Oxford ; New York: Oxford University Press.

Zhou, L., Furuta, T., and Kaneko, T. (2003). Chemical organization of projection neurons in the rat accumbens nucleus and olfactory tubercle. Neuroscience 120 , 783-798. doi: 10.1016/s0306-4522(03)00326-9

Zorrilla, E. P., and Koob, G. F. (2013). Amygdalostriatal projections in the neurocircuitry for motivation: a neuroanatomical thread through the career of Ann Kelley. Neurosci. Biobehav. Rev. 37, 1932-1945. doi: 10.1016/j.neubiorev. 2012.11.019

Conflict of Interest Statement: The authors declare that the research was conducted in the absence of any commercial or financial relationships that could be construed as a potential conflict of interest.

Copyright (C) 2015 Wood and Ahmari. This is an open-access article distributed under the terms of the Creative Commons Attribution License (CC BY). The use, distribution and reproduction in other forums is permitted, provided the original author(s) or licensor are credited and that the original publication in this journal is cited, in accordance with accepted academic practice. No use, distribution or reproduction is permitted which does not comply with these terms. 